Research Article

\title{
Dynamic Response of Rock Slopes under Obliquely Incident Seismic Waves
}

\author{
Biao Liu $\mathbb{D D}^{1,2}$ and Boyan Zhang $\mathbb{D I D}^{1,2}$ \\ ${ }^{1}$ China Institute of Water Resources and Hydropower Research, Beijing 100048, China \\ ${ }^{2}$ State Key Laboratory of Simulation and Regulation of Water Cycle in River Basin, Beijing 100048, China \\ Correspondence should be addressed to Boyan Zhang; zhangboyan2008@163.com
}

Received 1 July 2020; Revised 11 August 2020; Accepted 26 August 2020; Published 16 September 2020

Academic Editor: Jia-Wen Zhou

Copyright (C) 2020 Biao Liu and Boyan Zhang. This is an open access article distributed under the Creative Commons Attribution License, which permits unrestricted use, distribution, and reproduction in any medium, provided the original work is properly cited.

\begin{abstract}
In this study, the seismic input model of slope is proposed to investigate the dynamic response of the rock slope under obliquely incident seismic wave on the basis of the time-domain wave analysis method. The model includes viscoelastic boundary considering the infinite foundation radiation damping and the seismic obliquely incident method. The semi-infinite space numerical example is simulated to verify the validity and accuracy of the model. Based on the established model, the effects of the variation of the seismic wave incident angles and slope angles on the dynamic response of a rock slope are analyzed. The results demonstrate that the changes of the incident angle and the slope angle have no discernible effect on the dynamic response of the rock slope when the $\mathrm{P}$ wave is obliquely incident. As the SV wave is obliquely incident, the peak ground acceleration amplification coefficient along the slope surface gradually increases with the increase of the incident angle; when the slope angle gradually increases, the peak ground acceleration amplification coefficient along the slope surface will also gradually increase at the upper part of the slope. The research results can provide some basis for the pseudostatic method to determine the seismic action coefficient.
\end{abstract}

\section{Introduction}

Earthquake-induced rock slope damage is one of the most widespread and dangerous geological disasters in the world. Large-scale collapses and landslides induced by earthquakes such as the $1999 \mathrm{Mw}=7.7 \mathrm{Chi}-\mathrm{Chi}$ earthquake (Taiwan) $[1,2]$, the $2008 \mathrm{Mw} 7.9$ Wenchuan earthquake (China) [3, 4], the 2017 Mw 7.1 Puebla City earthquake (Mexico) [5-7], and so on [8], caused serious losses to people's lives and property safety. The western region of China is located in the high seismic intensity area where strong earthquakes occur frequently. With the construction of a large number of hydropower projects in the western region, the problem of slope dynamic stability under seismic action has become more and more prominent. At present, significant progress has been achieved in regard to the slope static stability analysis of water resources and hydropower engineering, while the comparatively unsubstantial part is the dynamic slope stability analysis under the action of intense earthquakes [9]. Hence, the seismic stability analysis of the slope has grown up to be a hot issue to be urgently solved in the construction of engineering. Reasonable slope seismic input mechanism and the amplification effect of earthquakes along the slope are the precondition of seismic stability analysis of slope. However, there are no explicit provisions on these two aspects of the three existing Chinese codes related to the slope of water conservancy and hydropower projects [9], which makes it more difficult to study the slope seismic resistant design.

In the last few decades, numerous studies [10-14] have been performed investigating the influence of rock slope dynamic response under earthquake in the domestic and overseas. Bouckovalas and Papadimitriou [10] analyzed the topography effects for step-like slopes under vertical SV seismic wave and proposed that the slope topography effect can alter the peak horizontal seismic ground acceleration 
near the crest of the slope. Bourdeau and Havenith [11] conducted a sensitivity analysis of slope site effects based on the finite difference method and found that different slope site conditions had different amplification effects on seismic waves. Yang et al. [12] designed and completed a large-scale shaking table model test to analyze the dynamic response and failure characteristics of antidip rock slope and found that acceleration sharply increased around the slope surface and crest as the model height and shaking intensity increased. Although many qualitative researches have been done to study earthquake amplification effect of slopes, it is unclear to quantitatively study earthquake amplification effect of slopes. In addition, the above study assumes that seismic waves are shear waves or compression waves which are incident perpendicularly from the substrate. This is reasonable for far-field sources, but for near-field sources, the seismic waves from the hypocenter, through the complex propagation process in the crustal media, after multiple refraction and reflection, propagate to the ground at certain incident angles but not vertically $[15,16]$. Through mutual verification of numerical simulation results and field survey data, Alfaro found that the interaction between the slope and the obliquely propagating seismic waves was the cause of landslides triggered by earthquakes. Moreover, only for seismic waves with incidence angles in the range $0^{\circ}-50^{\circ}$, the rockslide is most likely to be triggered, and the effect of incident angle on dynamic response of rock slope cannot be ignored [17].

On the other hand, many references can be found in the literature confirming the influence of obliquely incident seismic waves in near-field problems of structures and ground motions [18-22]. García et al. [19] studied the influence of the incident direction of seismic waves on the dynamic response of arch dams and indicated that the seismic response generated by oblique incidence was significantly larger than that generated by vertical incidence, which suggests that analyses considering only vertical incidence may underestimate the seismic response of such structures. Yan et al. [20] studied the seismic response characteristics of the tunnel under the action of obliquely incident seismic wave and found that the seismic response of the tunnel under oblique excitation was quite different from that under vertical excitation, and the former was more unfavorable. These studies show that there are significant differences in the dynamic responses of structures between the vertical and obliquely incident seismic waves. Nevertheless, the research on the dynamic response of rocky slopes under the condition of obliquely incident seismic waves is extremely limited.

This research applied seismic wave incidence theory combined with the stress-type viscous-spring boundary under the premise of considering the radiation damping effects of the infinite foundation, adopted the equivalent load at the boundary node to realize the wave input of obliquely incident seismic wave, and subsequently proposed the seismic input model of slope that is suitable for the analysis of slope dynamic response under the action of obliquely incident $\mathrm{P}$ waves and SV waves. Furthermore, the rock slope dynamic response law of the obliquely incident plane $\mathrm{P}$ wave and SV wave under different slope angles is summarized by analyzing and summarizing the numerical simulation results.

\section{The Seismic Input Model of Slope}

The main factor leading to landslide movement is the interaction between seismic waves and slope, which involves slope stability and local site seismic amplification [23]. Generally speaking, the instability of rock slope is caused by $\mathrm{P}$ wave and SV wave. Since P wave has only volume deformation but no distortion in the process of propagation, it is also called longitudinal wave or compression waves. Its propagation characteristic is that the vibration direction is the same as the wave propagation direction. The SV wave has only shapes change and no volume deformation during propagation, and it is also called shear wave or transverse wave. Its characteristic is the case that the propagation direction and vibration direction is perpendicular to each other. P wave propagates faster than SV wave. When the seismic wave propagates to the slope, the rock slope first generates vertical vibration under the action of longitudinal waves, causing lateral cracks on the slope surface, which weakens the stability of the rock slope. Secondly, the strong horizontal shaking of the shear wave caused landslides and collapses [24]. Landslide and collapse under the action of earthquakes are the main manifestation of the geological hazard of slope. The study of the dynamic stability of a slope is helpful to prevent the occurrence of such hazard. The dynamic stability analysis of slope usually includes two main problems: one is the input method of seismic wave, and the other is the dynamic response of the structure. In order to do some in-depth study of the subject, the seismic input model of slope based on time-domain wave analysis method is constructed, including viscoelastic boundary considering the radiation damping effects of the infinite foundation and seismic wave input method, as illustrated in Figure 1. This model was utilized to study the dynamic amplification response of the rock slope under the obliquely incident seismic wave, which provides the basis for the slope stability analysis.

2.1. Viscoelastic Boundary. Dynamic response analysis of a rock slope is normally an open-system fluctuation problem, that is, the near-field fluctuation problem. The fluctuations in the structure and the foundation of the finite field have an impact on the engineering problems we are concerned about. For the fluctuation problem of the infinite domain foundation, this paper only studies its influence on the fluctuation of the finite field. Therefore, when the numerical method is used to simulate the dynamic analysis of the structure, it is often used to simulate the propagation of seismic waves to the infinite domain by cutting off the computational region of a limited range from the semiinfinite space. However, in the process of seismic wave escaping to the infinite domain, the outward-spreading waves will reflect at the truncated boundary, and the dynamic response of the analysis area will be artificially increased. In order to eliminate the reflection of the truncated 


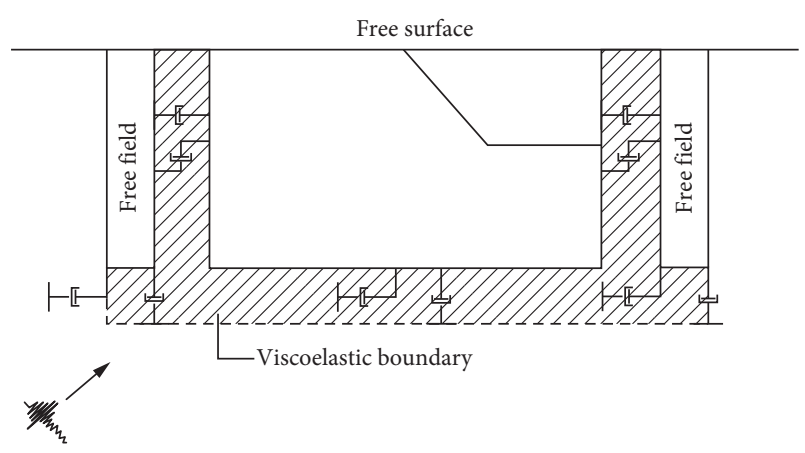

FIgURE 1: The seismic input model of slope.

boundary and simulate the radiation damping effect of the infinite foundation, an appropriate artificial boundary must be added to the truncated boundary. The artificial boundary can completely absorb or transmit the outward-spreading transmission wave without any reflection effect, so that the propagation characteristics of the outward-spreading wave can be consistent with the original continuum when it passes through the artificial boundary. At present, the commonly used artificial boundaries are transmission boundary [25], viscous boundary [26] and viscoelastic boundaries $[18,27-30]$, etc. Compared with other artificial boundaries, the viscoelastic boundary can simulate not only the absorption of the infinite foundation to energy of scattered wave, but also the elastic recovery ability of the infinite foundation $[31,32]$, so it has been widely used.

In the viscoelastic boundary, a series of viscous damping and linear springs are simultaneously installed on the artificial boundary in the tangential and normal directions. The spring stiffness coefficient and viscous damping coefficient at the two-dimensional artificial boundary are calculated according to the following expression:

$$
\left\{\begin{array}{l}
K_{\mathrm{BT}}=A_{B} \cdot \frac{G}{2 r_{B}}, \\
C_{\mathrm{BT}}=\rho c_{s} \cdot A_{B}, \\
K_{\mathrm{BN}}=A_{B} \cdot \frac{E}{2 r_{B}}, \\
C_{\mathrm{BN}}=\rho c_{p} \cdot A_{B},
\end{array}\right.
$$

where $K_{\mathrm{BT}}$ and $K_{\mathrm{BN}}$ are the tangential and normal spring constants, respectively; $C_{\mathrm{BT}}$ and $C_{\mathrm{BN}}$ are the tangential and normal damping coefficients, respectively; $\rho$ is the mass density; $E$ is the elastic modulus; $G$ is the shear modulus; $c_{p}$ and $c_{s}$ are the velocity of the $\mathrm{P}$ and SV wave, respectively; and $r_{B}$ is the distance between the scattering source and the artificial boundary [33].

2.2. Input Method of Obliquely Incident Seismic Waves. In order to ensure the safety of rock slope under the action of near-field earthquake, a reasonable ground motion input method is a paramount basis for accurate seismic stability analysis of rock slope. The existing seismic input methods mainly include the standard-rigid-base input model, the massless-foundation input model, the deconvolved-baserock input model, and free-field input model $[34,35]$. For the seismic stability analysis of a rock slope, it is indispensable to simulate not only the topographic and geological conditions of the site, but also the internal sliding generated by slope movement and the radiation damping effects of the infinite foundation. Therefore, it is more reasonable to use the free-field input model, and it is compatible with the wave method. The finite element equation of the slope seismic input model can be expressed as

$$
\mathbf{M} \ddot{u}+\mathbf{C} \dot{u}+\mathbf{K u}=\mathbf{F}_{B},
$$

where $\ddot{u}, \dot{u}$, and $\mathbf{u}$ are the acceleration vector, velocity vector, and displacement vector of the system, respectively; M, C, and $\mathbf{K}$ are the total mass matrix, the total damping matrix, and the total stiffness matrix of the structural system, respectively; and $\mathbf{F}_{B}$ is the force load acting on the artificial boundary by seismic waves.

The finite element equation (2) is discretized in the timedomain using the center difference method. The difference format is

$$
\begin{aligned}
& \ddot{u}^{t}=\frac{1}{2 \Delta t}\left(\mathbf{u}^{t+\Delta t}-\mathbf{u}^{t-\Delta t}\right), \\
& \ddot{u}^{t}=\frac{1}{\Delta t^{2}}\left(\mathbf{u}^{t+\Delta t}-2 \mathbf{u}^{t}+\mathbf{u}^{t-\Delta t}\right),
\end{aligned}
$$

in which the superscript $t$ represents the time, and $\Delta t$ is the time interval. Substituting (3) and (4) into (2), the step-bystep calculation formula can be obtained as follows:

$$
\begin{aligned}
\left(\frac{1}{\Delta t^{2}} \mathbf{M}+\frac{1}{2 \Delta t} \mathbf{C}\right) \mathbf{u}^{t+\Delta t}= & \mathbf{F}^{t}-\left(\mathbf{K}-\frac{2}{\Delta t^{2}}\right) \mathbf{u}^{t} \\
& -\left(\frac{1}{\Delta t^{2}} \mathbf{M}-\frac{1}{2 \Delta t} \mathbf{C}\right) \mathbf{u}^{t-\Delta t} .
\end{aligned}
$$

In (5), $\mathbf{F}^{t}$ refers to the force load of seismic wave at the artificial boundary at time $t$. This research utilized free-field input model based on viscoelastic boundary, decomposed the wave field in the finite domain into a free field and a scattered field, and subsequently converted the displacement and velocity of seismic wave into equivalent nodal forces that applied at the boundary nodes to realize the wave input of obliquely incident seismic wave. Hence, the seismic motion input can be realized by applying the equivalent load to the boundary nodes which includes the force required by the spring-damping element to absorb the scattering wave and the boundary force generated by the free-field motion at the boundary node. The equivalent nodal force acting on the artificial boundary node can be expressed as

$$
\mathbf{F}_{\mathrm{B}}=\mathbf{K}_{\mathrm{B}} \mathbf{u}_{\mathrm{B}}^{\mathrm{ff}}+\mathbf{C}_{\mathrm{B}} \dot{u}_{\mathrm{B}}^{\mathrm{ff}}+\mathbf{\sigma}_{\mathrm{B}}^{\mathrm{ff}} \mathbf{n} \mathbf{A}_{\mathrm{B}}
$$

in which subscript $B$ denotes the boundary node number; $A_{B}$ is the affected area of the boundary node; and $\mathrm{n}$ is the cosine vector of the boundary outer normal direction. According to 
(1), $K_{B}$ and $C_{B}$ are the spring stiffness matrix and the damping coefficient matrix of the viscoelastic boundary, respectively. $\mathbf{K}_{\mathrm{B}}=\left[\begin{array}{lll}K_{\mathrm{BT}} & K_{\mathrm{BN}}\end{array}\right]^{T} ; \mathbf{C}_{\mathbf{B}}=\left[\begin{array}{lll}C_{\mathrm{BT}} & C_{\mathrm{BN}}\end{array}\right]^{T} . \mathbf{u}_{\mathrm{B}}^{\mathrm{ff}}$, $\dot{u}_{\mathrm{B}}^{\mathrm{ff}}$, and $\sigma_{\mathrm{B}}^{\mathrm{ff}}$ are the free-field displacement vectors, velocity vectors, and stress tensor at the boundary nodes, respectively. The solution of these three vectors is the key to the derivation of the equivalent load calculation formula. The following formulas are derived for calculating the equivalent load of the boundary nodes under the obliquely incident $\mathrm{P}$ wave and SV wave.

2.3. Derivation of Equivalent Loads Induced by $P$ Waves. It can be seen from the wave theory that waveform conversion occurs when the seismic wave propagates to the free surface [36]. When the $\mathrm{P}$ wave is obliquely incident on the free surface with the angle of $\alpha, P$ wave with a reflection angle $\alpha$ and SV wave with a reflection angle $\beta$ are derived, as shown in Figure 2. Set the displacement of the incident $P$ wave as $u_{p}(t)$, and the finite height of the foundation as $H$ and the width as $L$. Assuming that the $\mathrm{P}$ wave and its reflected wave have no attenuation in the propagation of a plane half-space medium, according to Snell's law, the incident angle, the reflection angle, and the amplitude have the following relationship:

$$
\left\{\begin{array}{l}
\sin \beta=\frac{c_{s} \sin \alpha}{c_{p}} \\
A_{1}=\frac{c_{s}^{2} \sin 2 \alpha \sin 2 \beta-c_{p}^{2} \cos ^{2} 2 \beta}{c_{s}^{2} \sin 2 \alpha \sin 2 \beta+c_{p}^{2} \cos ^{2} 2 \beta} \\
A_{2}=\frac{2 c_{p} c_{s} \sin 2 \alpha \cos 2 \beta}{c_{s}^{2} \sin 2 \alpha \sin 2 \beta+c_{p}^{2} \cos ^{2} 2 \beta}
\end{array}\right.
$$

where $A_{1}$ and $A_{2}$ are the amplitude ratio of the reflected $\mathrm{P}$ wave and the reflected $S V$ wave to the incident $\mathrm{P}$ wave, respectively.

After obtaining the amplitude of the incident wave and the reflected wave, the time lag is determined according to the position of the space point and the wave velocity, and the delay between wave propagation processes is considered. Assuming an arbitrary point in finite area $(x, y)$ (where $0 \leq x \leq L, 0 \leq y \leq H)$, the time delays of the incident $\mathrm{P}$ wave, reflected $\mathrm{P}$ wave, and reflected $\mathrm{SV}$ wave with respect to the wave front are $\Delta t_{1}, \Delta t_{2}$, and $\Delta t_{3}$, respectively:

$$
\left\{\begin{array}{l}
\Delta t_{1}=\frac{x \sin \alpha+y \cos \alpha}{c_{p}}, \\
\Delta t_{2}=\frac{(2 H-y) \cos \alpha+x \sin \alpha}{c_{p}}, \\
\Delta t_{3}=\frac{[H \cos \alpha-(H-y) \tan \beta \sin \alpha+x \sin \alpha]}{c_{p}}+\frac{(H-y)}{c_{s} \cos \beta} .
\end{array}\right.
$$

The displacement and velocity of the free field of the boundary point can be obtained by the superposition principle of waves, and the displacement and velocity of the free field of the artificial boundary point can be expressed as

$$
\left\{\begin{array}{l}
u_{B}(x, y, t)=u_{p}\left(x, y, t-\Delta t_{1}\right) \sin \alpha+A_{1} u_{p}\left(x, y, t-\Delta t_{2}\right) \sin \alpha+A_{2} u_{p}\left(x, y, t-\Delta t_{3}\right) \cos \beta, \\
v_{B}(x, y, t)=u_{p}\left(x, y, t-\Delta t_{1}\right) \cos \alpha-A_{1} u_{p}\left(x, y, t-\Delta t_{2}\right) \cos \alpha+A_{2} u_{p}\left(x, y, t-\Delta t_{3}\right) \sin \beta, \\
\dot{u}_{B}(x, y, t)=\dot{u}_{p}\left(x, y, t-\Delta t_{1}\right) \sin \alpha+A_{1} \dot{u}_{p}\left(x, y, t-\Delta t_{2}\right) \sin \alpha+A_{2} \dot{u}_{p}\left(x, y, t-\Delta t_{3}\right) \cos \beta, \\
\dot{v}_{B}(x, y, t)=\dot{u}_{p}\left(x, y, t-\Delta t_{1}\right) \cos \alpha-A_{1} \dot{u}_{p}\left(x, y, t-\Delta t_{2}\right) \cos \alpha+A_{2} \dot{u}_{p}\left(x, y, t-\Delta t_{3}\right) \sin \beta,
\end{array}\right.
$$

where $u_{B}(x, y, t)$ and $v_{B}(x, y, t)$ are, respectively, the horizontal and vertical displacements; $\dot{u}_{B}(x, y, t)$ and $\dot{v}_{B}(x, y, t)$ are, respectively, the horizontal and vertical velocity of the free wave field at the artificial boundary point when the $P$ wave with a displacement of $u_{p}(t)$ is incident with the angle of $\alpha$.
The propagation stress of the free field is transformed from the local coordinate system to the global coordinate system, and the stress on the artificial boundary is obtained. The stress $\sigma_{B 1}$ generated by the incident $\mathrm{P}$ wave with the angle of $\alpha$ is 


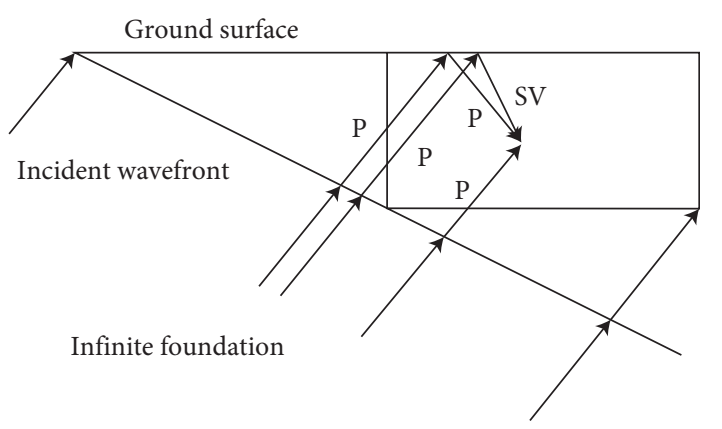

(a)

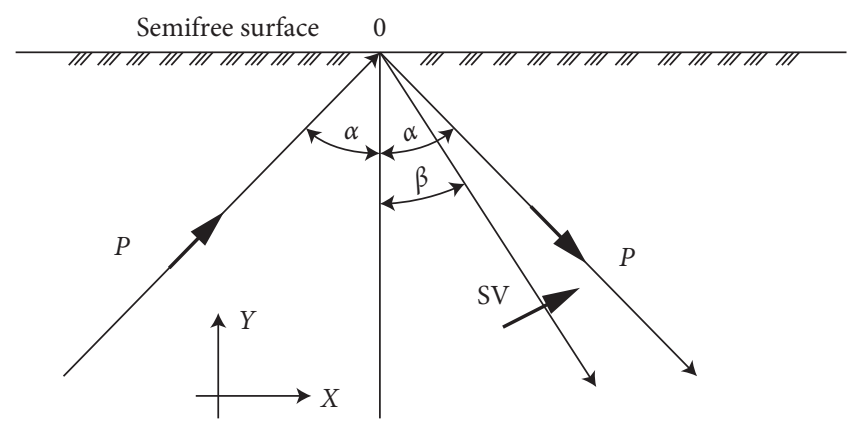

Positive vibration direction

$\rightarrow$ Direction of propagation

(b)

Figure 2: Oblique incidence of plane P wave. (a) Oblique incidence model. (b) Reflection of waves on free surface.

$$
\boldsymbol{\sigma}_{B 1}=\left(\begin{array}{cc}
\sigma_{x 1} & \tau_{x y 1} \\
\tau_{y x 1} & \sigma_{y 1}
\end{array}\right),\left\{\begin{array}{l}
\sigma_{x 1}=\left(\sigma_{\xi} \sin ^{2} \alpha+\sigma_{\eta} \cos ^{2} \alpha\right)=-\frac{\lambda+2 G \sin ^{2} \alpha}{c_{p}} \dot{u}_{p}\left(x, y, t-\Delta t_{1}\right), \\
\tau_{x y 1}=-\left(\sigma_{\eta}-\sigma_{\xi}\right) \sin \alpha \cos \alpha=-\frac{G \sin 2 \alpha}{c_{p}} \dot{u}_{p}\left(x, y, t-\Delta t_{1}\right), \\
\sigma_{y 1}=\left(\sigma_{\xi} \cos ^{2} \alpha+\sigma_{\eta} \sin ^{2} \alpha\right)=-\frac{\lambda+2 G \cos ^{2} \alpha}{c_{p}} \dot{u}_{p}\left(x, y, t-\Delta t_{1}\right),
\end{array}\right.
$$

where $\sigma_{\xi}$ is the stress of plane wave propagation direction in local coordinate system; $\sigma_{\eta}$ is the normal stress of plane wave propagation direction in local coordinate system; and $\tau_{x y}$ is the shear stress of plane wave propagation direction in the local coordinate system [9], $\tau_{y x}=\tau_{x y}$.

The stress $\sigma_{B 2}$ generated by the reflected $\mathrm{P}$ wave with the reflection angle of $\alpha$ is

$$
\boldsymbol{\sigma}_{B 2}=\left(\begin{array}{cc}
\sigma_{x 2} & \tau_{x y 2} \\
\tau_{y x 2} & \sigma_{y 2}
\end{array}\right),\left\{\begin{array}{l}
\sigma_{x 2}=\left(\sigma_{\xi} \sin ^{2} \alpha+\sigma_{\eta} \cos ^{2} \alpha\right)=-A_{1} \frac{\lambda+2 G \sin ^{2} \alpha}{c_{p}} \dot{u}_{p}\left(x, y, t-\Delta t_{2}\right), \\
\tau_{x y 2}=\left(\sigma_{\eta}-\sigma_{\xi}\right) \sin \alpha \cos \alpha=A_{1} \frac{G \sin 2 \alpha}{c_{p}} \dot{u}_{p}\left(x, y, t-\Delta t_{2}\right), \\
\sigma_{y 2}=\left(\sigma_{\xi} \cos ^{2} \alpha+\sigma_{\eta} \sin ^{2} \alpha\right)=-A_{1} \frac{\lambda+2 G \cos ^{2} \alpha}{c_{p}} \dot{u}_{p}\left(x, y, t-\Delta t_{2}\right) .
\end{array}\right.
$$

The stress $\sigma_{B 3}$ generated by the reflected SV wave with the reflection angle of $\beta$ is 


$$
\sigma_{B 3}=\left(\begin{array}{cc}
\sigma_{x 3} & \tau_{x y 3} \\
\tau_{y x 3} & \sigma_{y 3}
\end{array}\right), \quad\left\{\begin{array}{l}
\sigma_{x 3}=2 \tau_{\xi \eta} \sin \beta \cos \beta=-A_{2} \frac{G \sin 2 \beta}{c_{s}} \dot{u}_{p}\left(x, y, t-\Delta t_{3}\right), \\
\tau_{x y 3}=\tau_{\xi \eta}\left(\sin ^{2} \beta-\cos ^{2} \beta\right)=A_{2} \frac{G \cos 2 \beta}{c_{s}} \dot{u}_{p}\left(x, y, t-\Delta t_{3}\right), \\
\sigma_{y 3}=-2 \tau_{\xi \eta} \sin \beta \cos \beta=A_{2} \frac{G \sin 2 \beta}{c_{s}} \dot{u}_{p}\left(x, y, t-\Delta t_{3}\right) .
\end{array}\right.
$$

The total stress of free-field boundary is

$$
\boldsymbol{\sigma}_{B}=\sigma_{B 1}+\sigma_{B 2}+\sigma_{B 3} .
$$

\subsection{Derivation of Equivalent Loads Induced by SV Waves.} Similar to the P wave incident method, the displacement of the incident SV wave is assumed to be $u_{s}\left(t^{\prime}\right)$. When the SV wave is obliquely incident on the free surface with the angle of $\alpha^{\prime}, \mathrm{SV}$ wave with a reflection angle $\alpha^{\prime}$ and $P$ wave with a reflection angle $\beta \prime$ are derived, as shown in Figure 3. Assuming that the SV wave and its reflected wave have no attenuation in the propagation of a plane half-space medium, according to Snell's law, the incident angle, the reflection angle, and the amplitude have the following relationship:

$$
\left\{\begin{array}{l}
\sin \beta \prime=\frac{c_{p} \sin \alpha^{\prime}}{c_{s}}, \\
B_{1}=\frac{c_{s}^{2} \sin 2 \alpha^{\prime} \sin 2 \beta \prime-c_{p}^{2} \cos ^{2} 2 \alpha^{\prime}}{c_{s}^{2} \sin 2 \alpha^{\prime} \sin 2 \beta^{\prime}+c_{p}^{2} \cos ^{2} 2 \alpha^{\prime}} \\
B_{2}=\frac{2 c_{s} c_{p} \sin 2 \alpha^{\prime} \cos 2 \alpha^{\prime}}{c_{s}^{2} \sin 2 \alpha^{\prime} \sin 2 \beta^{\prime}+c_{p}^{2} \cos ^{2} 2 \alpha^{\prime}}
\end{array}\right.
$$

where $B_{1}$ and $B_{2}$ are the amplitude ratio of the reflected SV wave and the reflected $\mathrm{P}$ wave to the incident SV wave, respectively. It should be noted that when the SV wave is obliquely incident at a certain angle, there is an incident critical angle. When the incident angle of the SV wave is larger than the critical angle, the reflected wave losses the property of the plane wave and becomes a nonuniform wave. For the calculation model of this paper, the critical angle can be obtained from the calculation parameters:

$$
\alpha_{\mathrm{cr}}<\arcsin \left(\frac{c_{s}}{c_{p}}\right) \text {. }
$$

After obtaining the amplitudes of the incident wave and the reflected wave, the time lag is determined according to the position of the space point and the wave velocity, and the delay between wave propagation processes is considered. Assuming an arbitrary point $(x, y)$ (where $0 \leq x \leq L$, $0 \leq y \leq H)$, the time delays of the incident SV wave, reflected SV wave, and reflected $\mathrm{P}$ wave with respect to the wave front are $\Delta t_{1}^{\prime}, \Delta t_{2}^{\prime}$, and $\Delta t_{3}^{\prime}$, respectively:

$$
\left\{\begin{array}{l}
\Delta t_{1}^{\prime}=\frac{x \sin \alpha \prime+y \cos \alpha^{\prime}}{c_{s}} \\
\Delta t_{2}^{\prime}=\frac{(2 H-y) \cos \alpha^{\prime}+x \sin \alpha^{\prime}}{c_{s}} \\
\Delta t_{3}^{\prime}=\frac{\left[H \cos \alpha \prime-(H-y) \tan \beta^{\prime} \sin \alpha^{\prime}+x \sin \alpha^{\prime}\right]}{c_{s}}+\frac{(H-y)}{c_{p} \cos \beta^{\prime}}
\end{array}\right.
$$

The displacement and velocity of the free field of the boundary point can be obtained by the superposition principle of waves, and the displacement and velocity of the free field of the artificial boundary point can be expressed as

$$
\left\{\begin{array}{l}
u_{B}^{\prime}\left(x, y, t^{\prime}\right)=u_{s}\left(x, y, t^{\prime}-\Delta t_{1}^{\prime}\right) \cos \alpha^{\prime}-B_{1} u_{s}\left(x, y, t^{\prime}-\Delta t_{2}^{\prime}\right) \cos \alpha^{\prime}+B_{2} u_{s}\left(x, y, t^{\prime}-\Delta t_{3}^{\prime}\right) \sin \beta \prime \\
v_{B}^{\prime}\left(x, y, t^{\prime}\right)=-u_{s}\left(x, y, t^{\prime}-\Delta t_{1}^{\prime}\right) \sin \alpha^{\prime}-B_{1} u_{s}\left(x, y, t^{\prime}-\Delta t_{2}^{\prime}\right) \sin \alpha^{\prime}-B_{2} u_{s}\left(x, y, t^{\prime}-\Delta t_{3}^{\prime}\right) \cos \beta^{\prime}, \\
\dot{u}_{B}^{\prime}\left(x, y, t^{\prime}\right)=\dot{u}_{s}\left(x, y, t^{\prime}-\Delta t_{1}^{\prime}\right) \cos \alpha^{\prime}-B_{1} \dot{u}_{s}\left(x, y, t^{\prime}-\Delta t_{2}^{\prime}\right) \cos \alpha^{\prime}+B_{2} \dot{u}_{s}\left(x, y, t^{\prime}-\Delta t_{3}^{\prime}\right) \sin \beta \prime \\
\dot{v}_{B}^{\prime \prime}\left(x, y, t^{\prime}\right)=-\dot{u}_{s}\left(x, y, t^{\prime}-\Delta t_{1}^{\prime}\right) \sin \alpha^{\prime}-B_{1} \dot{u}_{s}\left(x, y, t^{\prime}-\Delta t_{2}^{\prime}\right) \sin \alpha^{\prime}-B_{2} \dot{u}_{s}\left(x, y, t^{\prime}-\Delta t_{3}^{\prime}\right) \cos \beta \prime
\end{array}\right.
$$

where $u_{B}^{\prime}\left(x, y, t^{\prime}\right)$ and $v_{B}^{\prime}\left(x, y, t^{\prime}\right)$ are, respectively, the horizontal and vertical displacements; $\dot{u}_{B}^{\prime}\left(x, y, t^{\prime}\right)$ and $\dot{v}_{B}^{\prime}\left(x, y, t^{\prime}\right)$ are, respectively, the horizontal and vertical velocity of the free wave field at the artificial boundary point when the SV wave with a displacement of $u_{s}\left(t^{\prime}\right)$ is incident with the angle of $\alpha^{\prime}$. 


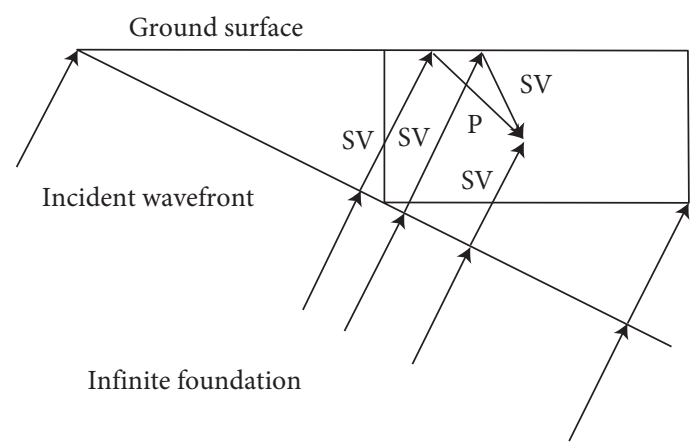

(a)

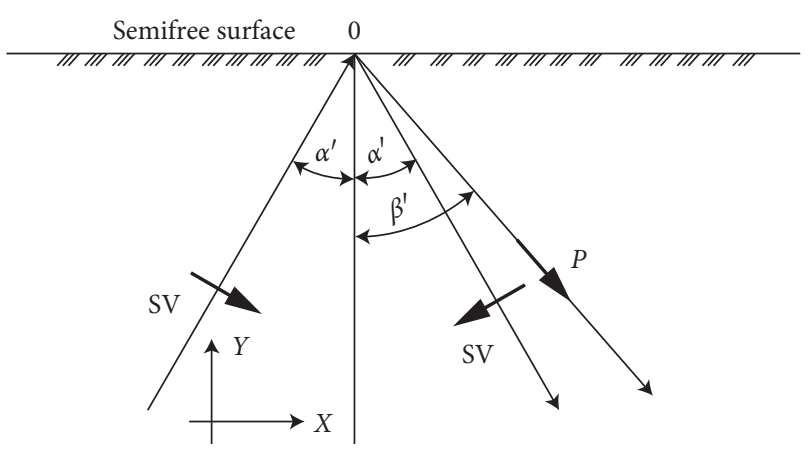

Positive vibration direction

Direction of propagation

(b)

FIgURE 3: Oblique incidence of plane SV wave. (a) Oblique incidence model. (b) Reflection of waves on free surface.

According to the displacement of the plane wave, the stress on the artificial boundary is determined by one-point stress state formula. The stress $\sigma_{B 1}^{\prime}$ generated by the incident SV wave with the angle of $\alpha^{\prime}$ is

$$
\boldsymbol{\sigma}_{B 1}^{\prime}=\left(\begin{array}{cc}
\sigma_{x 1}^{\prime} & \tau_{x y 1}^{\prime} \\
\tau_{y x 1}^{\prime} & \sigma_{y 1}^{\prime}
\end{array}\right), \quad\left\{\begin{array}{l}
\sigma_{x 1}^{\prime}=2 \tau_{\xi \eta}^{\prime} \sin \alpha \prime \cos \alpha \prime=-\frac{G \sin 2 \alpha \prime}{c_{s}} \dot{u}_{s}\left(x, y, t \prime-\Delta t_{1}^{\prime}\right), \\
\tau_{x y 1}^{\prime}=\tau_{\xi \eta}^{\prime}\left(\cos ^{2} \alpha \prime-\sin ^{2} \alpha \prime\right)=-\frac{G \cos 2 \alpha}{c_{s}} \dot{u}_{s}\left(x, y, t \prime-\Delta t_{1}^{\prime}\right), \\
\sigma_{y 1}^{\prime}=-2 \tau_{\xi \eta}^{\prime} \sin \alpha \prime \cos \alpha \prime=\frac{G \sin 2 \alpha \prime}{c_{s}} \dot{u}_{s}\left(x, y, t \prime-\Delta t_{1}^{\prime}\right) .
\end{array}\right.
$$

The stress $\sigma_{B 2}$ generated by the reflected SV wave with the reflection angle of $\alpha^{\prime}$ is

$$
\boldsymbol{\sigma}_{B 2}^{\prime}=\left(\begin{array}{cc}
\sigma_{x 2}^{\prime} & \tau_{x y 2}^{\prime} \\
\tau_{y x 2}^{\prime} & \sigma_{y 2}^{\prime}
\end{array}\right), \quad\left\{\begin{array}{l}
\sigma_{x 2}^{\prime}=-2 \tau_{\xi \eta}^{\prime} \sin \alpha \prime \cos \alpha \prime=B_{1} \frac{G \sin 2 \alpha \prime}{c_{s}^{\prime}} \dot{u}_{s}\left(x, y, t \prime-\Delta t_{2}^{\prime}\right), \\
\tau_{x y 2}^{\prime}=\tau_{\xi \eta}^{\prime}\left(\cos ^{2} \alpha \prime-\sin ^{2} \alpha \prime\right)=-B_{1} \frac{G \cos 2 \alpha \prime}{c_{s}^{\prime}} \dot{u}_{s}\left(x, y, t \prime-\Delta t_{2}^{\prime}\right), \\
\sigma_{y 2}^{\prime}=2 \tau_{\xi \eta}^{\prime} \sin \alpha \prime \cos \alpha \prime=-B_{1} \frac{G \sin 2 \alpha}{c_{s}^{\prime}} \dot{u}_{s}\left(x, y, t \prime-\Delta t_{2}^{\prime}\right) .
\end{array}\right.
$$

The stress $\sigma_{B 3}$ generated by the reflected $P$ wave with the reflection angle of $\beta$, is 


$$
\sigma_{B 3}^{\prime}=\left(\begin{array}{cc}
\sigma_{x 3}^{\prime} & \tau_{x y 3}^{\prime} \\
\tau_{y x 3}^{\prime} & \sigma_{y 3}^{\prime}
\end{array}\right),\left\{\begin{array}{l}
\sigma_{x 3}^{\prime}=\left(\sigma_{\xi}^{\prime} \sin ^{2} \beta^{\prime}+\sigma_{\eta}^{\prime} \cos ^{2} \beta^{\prime}\right)=-B_{2} \frac{\lambda^{\prime}+2 G \sin ^{2} \beta^{\prime}}{c_{p}^{\prime}} \dot{u}_{s}\left(x, y, t^{\prime}-\Delta t_{3}^{\prime}\right), \\
\tau_{x y 3}^{\prime}=\left(\sigma_{\eta}^{\prime}-\sigma_{\xi}^{\prime}\right) \sin \beta^{\prime} \cos \beta^{\prime}=B_{2} \frac{G \sin 2 \beta^{\prime}}{c_{p}^{\prime}} \dot{u}_{s}\left(x, y, t^{\prime}-\Delta t_{3}^{\prime}\right), \\
\sigma_{y 3}^{\prime}=\left(\sigma_{\xi}^{\prime} \cos ^{2} \beta^{\prime}+\sigma_{\eta}^{\prime} \sin ^{2} \beta^{\prime}\right)=-B_{2} \frac{\lambda^{\prime}+2 G \cos ^{2} \beta^{\prime}}{c_{p}^{\prime}} \dot{u}_{s}\left(x, y, t^{\prime}-\Delta t_{3}^{\prime}\right) .
\end{array}\right.
$$

The total stress of free field boundary is

$$
\boldsymbol{\sigma}_{B}^{\prime}=\boldsymbol{\sigma}_{B 1}{ }^{\prime}+\boldsymbol{\sigma}_{B 2}{ }^{\prime}+\boldsymbol{\sigma}_{B 3}{ }^{\prime} .
$$

On the bottom surface and both sides of the left and right, the cosine vector $\boldsymbol{n}$ outside the boundary direction varies with the boundary surface. It means that at any point on the left artificial boundary $(0, y)$ (where $0 \leq y \leq H), \boldsymbol{n}=[-1$ $0]^{\mathrm{T}}$; any point on the bottom artificial boundary $(x, 0)$ (where $0 \leq x \leq L), \boldsymbol{n}=[0-1]^{\mathrm{T}}$; and any point on the right artificial boundary $(L, y)$ (where $0 \leq y \leq H), \mathrm{n}=\left[\begin{array}{ll}1 & 0\end{array}\right]^{\mathrm{T}}$. The corresponding stress of boundary point can be obtained by taking the boundary point into the formula. Based on the abovementioned basic principles of the model, the corresponding MATLAB calculation program is compiled in this paper, which finishes the numerical simulation of the slope dynamic response under the obliquely incident seismic wave.

\section{Numerical Verification}

In order to verify the validity and calculation accuracy of the model, we adopted a truncated rectangular region of uniform elastic half space to simulate the propagation process of seismic waves, that is depicted in Figure 4, which has been studied by Liu and $\mathrm{Lu}$ [33] using other methods. The truncated region has a dimension with $\mathrm{Lx}=762 \mathrm{~m}$ and $\mathrm{Ly}=381 \mathrm{~m}$. The model medium has an elastic modulus of $13.23 \mathrm{GPa}$, a shear modulus of $5.292 \mathrm{GPa}$, a mass density $\rho$ of $2700 \mathrm{~kg} / \mathrm{m}^{3}$, and a Poisson ratio of 0.25 . The points A (381, $381), \mathrm{B}(381,190.5)$, and C $(381,0)$ are selected as the observation points. For the wave input, an impulse is adopted as the incident plane waves, as shown in Figure 5. The corresponding time history is defined as

$$
\dot{u}_{0}(t)=\frac{1}{2}[1-\cos (2 \pi f t)], \quad f=4,0 \leq t \leq 0.25 .
$$

3.1. Plane $P$ Wave Incident Example. The incident wave uses a compression wave unit velocity pulse (Figure 5), and the incident angles $0^{\circ}, 15^{\circ}$, and $30^{\circ}$ are selected, respectively. Figure 6 summarizes the contours of the time history of Y-velocity and corresponding analytic solution at observation point $\mathrm{A}$ under $\mathrm{P}$ waves with different incident angles. The numerical solution and analytic solution of the maximum Y-velocity of $\mathrm{P}$ wave at different incident angles are listed in Table 1. It can be seen from the figure that the numerical result is in good agreement with the analytic solution, and the error is within the allowable range. Therefore, these comparisons demonstrate that the present method has high calculation accuracy.

3.2. Plane SV Wave Incident Example. The incident wave uses a shear wave unit velocity pulse (Figure 5); the incident angles $0^{\circ}, 15^{\circ}$, and $30^{\circ}$ are selected, respectively. The time history of X-velocity and corresponding analytic solution at observation point $\mathrm{A}$ under different incident angles can be described in Figure 7. In the following, the vertical incidence (Figure $7(\mathrm{~d})$ ) is taken as an example for brief analysis. When being in vertical incidence, the $\mathrm{X}$-velocity of point $\mathrm{A}$ on the free surface is two times that of the incident value because of the reflection from the surface and the superposition of the incident wave and the reflected wave. After approximately $0.794 \mathrm{~s}$, the wave no longer reflects upward from the bottom due to the energy absorbing effect of the viscoelastic boundary, and the velocity response to each part of the model becomes zero. In contrast, for the oblique incidence of the seismic wave, there are some differences in amplitude and time delay of crest motions. It can be found that the calculation results agree with the results in these references well [33]. Therefore, it can be observed that the viscoelastic boundary has superior energy absorption effect and the accuracy of the procedure developed in this paper.

The numerical solution and analytic solution of the model monitoring point maximum $\mathrm{X}$-velocity of $\mathrm{SV}$ wave at vertical incidence and $15^{\circ}$ and $30^{\circ}$ oblique incidence are listed in Table 2. It can be seen from the table that the numerical solution is very close to the analytic solution and the error is within the allowable range, which once again verifies the effectiveness of using the slope seismic input model to solve the obliquely incident problem of seismic waves.

\section{Analysis of Slope Dynamic Response}

The study of the dynamics of rock slopes under earthquakes is a cross-disciplinary and complicated subject. Besides the complexity of earthquake motion, the physical and mechanical properties of the weak structural surfaces such as the nature of the rock, the inner layer of the rock mass, the faults and the joints, and their distribution scale in the rock mass will also affect the dynamic property of the rock slope and seismic response [37]. So, if all the factors are taken into 


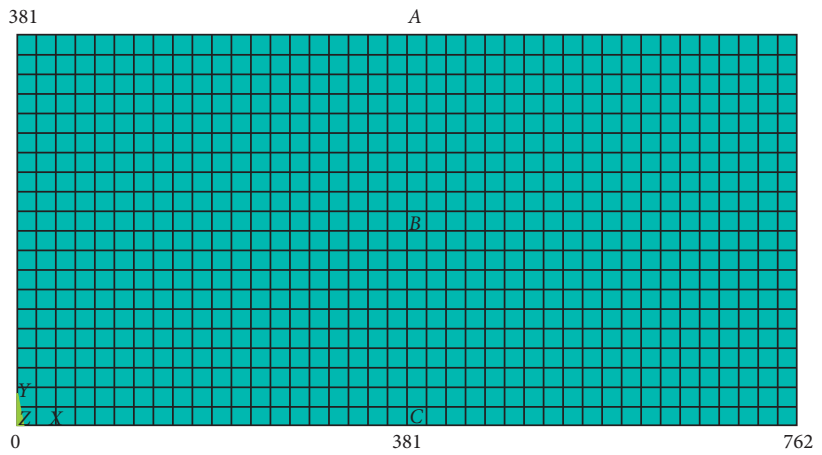

FIgURe 4: Computational model.

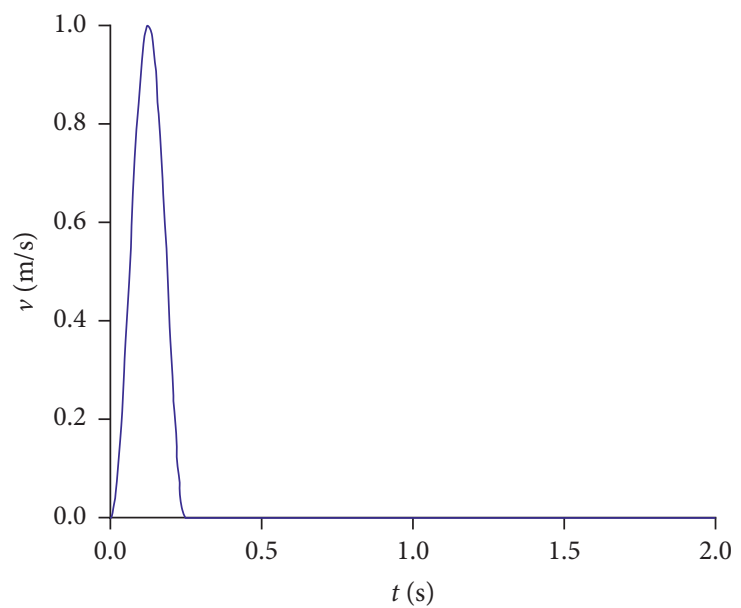

FIGURE 5: Velocity time history of input earthquake wave.

comprehensive and precise consideration, it will make the problem too complicated to be solved. In this paper, the rock slope will be simplified into a homogeneous and continuous elastic model for a study. Li et al. [37] have studied the distribution law of the seismic acceleration of the slope under the action of vertical incident seismic wave. For comparison, the same material parameters are selected to analyze the dynamic response of rock slope under the action of obliquely incident seismic wave. The simplified rock slope geometric model used in the numerical analysis is shown in Figure 8, and the corresponding finite element model is shown in Figure 9. The assumed mechanical properties of the rock mass are listed in Table 3. According to the code for engineering geological investigation of water resources and hydropower (GB50487-2008), the rock mass selected in this paper is classified as Class II. The height of the point on slope surface is $h$, and the relative height is defined as $h / H$, and slope angle $\theta$ is $45^{\circ}, 50^{\circ}$, and $60^{\circ}$. The time history of an artificial wave, of which the peak ground acceleration (PGA) is adjusted to $1 \mathrm{~m} / \mathrm{s}^{2}$ for facilitating the calculation, is generated by referring to standard design response spectrum according to the current Chinese standard for seismic design of hydraulic structures (GB51247-2018) with record duration of $11.99 \mathrm{~s}$ and time interval of $0.01 \mathrm{~s}$, as illustrated in Figure 10. The selected seismic wave is suitable for bedrock analysis, especially hard rock analysis.

The acceleration response and its distribution law of the slope are the basic data for evaluating the slope seismic response. The amplification coefficient of the peak ground acceleration (PGA) is defined as the ratio that is the peak acceleration at any point in the slope to that of the ground motion. To investigate the effects of the slope angle and incident angle on the acceleration amplification of rock slope seismic response, three slope configurations with a slope angle varying from $45^{\circ}$ to $60^{\circ}$ were modeled and subjected to numerical simulation under seismic waves with different incident angles of $\alpha=0^{\circ}, 15^{\circ}$, and $30^{\circ}$. The observation points are located at the slope surface AC and the vertical plane $A B$ at the crest of the slope. At the same time, a monitoring point $D$ is set on the free surface to compare and analyze the amplification effect generated on the surface and inside of the slope. According to the data recorded at each observation point, the distribution of the PGA amplification coefficient of rock slope under different slope angles is concluded when $\mathrm{P}$ wave and SV wave are obliquely incident. 


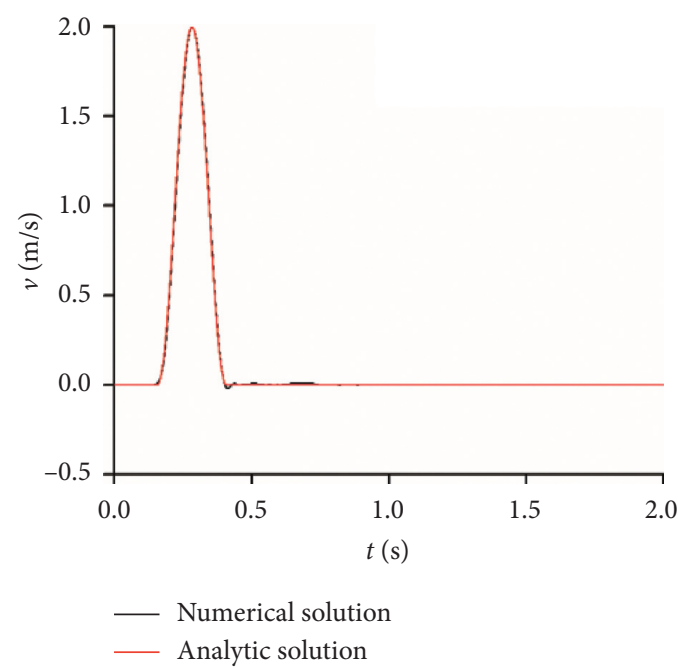

(a)

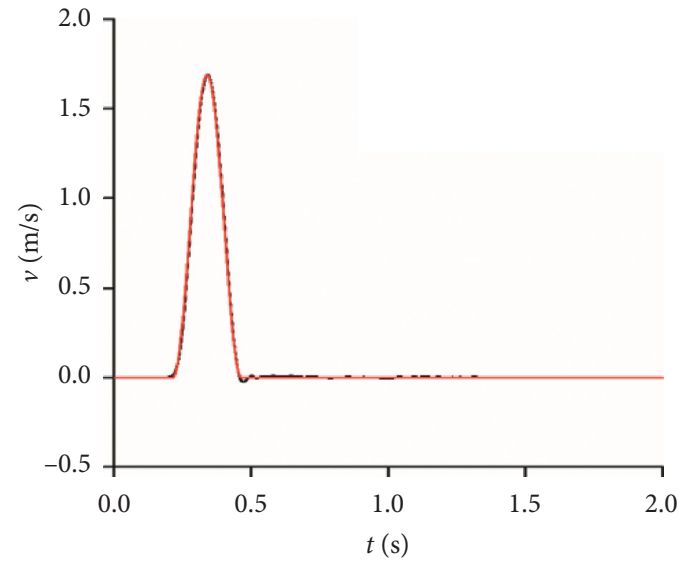

- Numerical solution

Analytic solution

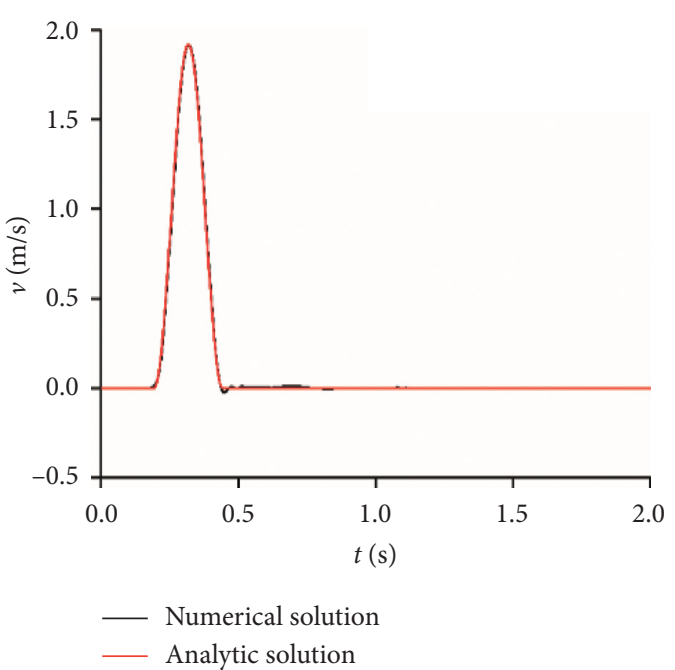

(b)

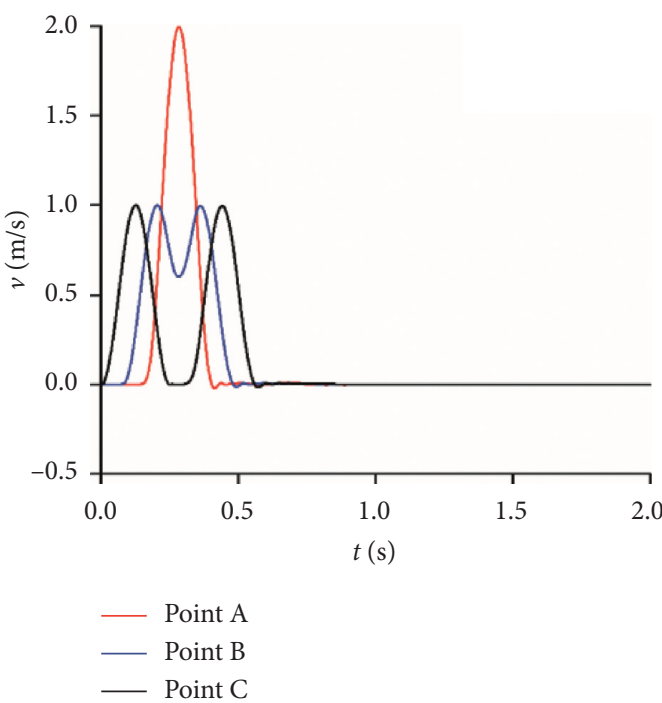

(d)

Figure 6: Time history of Y-velocity at observation points under different incident angles. (a) Point A under vertical incidence; (b) point A under $15^{\circ}$ oblique incidence; (c) point A under $30^{\circ}$ oblique incidence; and (d) observation points under vertical incidence.

TABLE 1: Maximum Y-velocity response and error of monitoring point at different incident angles.

\begin{tabular}{lcccc}
\hline Direction of incidence & Observation point & Numerical solution $(\mathrm{m} / \mathrm{s})$ & Analytic solution (m/s) & Relative error (\%) \\
\hline \multirow{3}{*}{$0^{\circ}$ incidence } & $\mathrm{C}$ & 1.0012 & 1.0000 & 0.12 \\
& $\mathrm{~B}$ & 1.0011 & 1.0000 & 0.11 \\
& $\mathrm{~A}$ & 1.9980 & 2.0000 & 0.1 \\
$15^{\circ}$ incidence & $\mathrm{C}$ & 0.9671 & 0.9659 & 0.9659 \\
& $\mathrm{~B}$ & 0.9668 & 1.9186 & 0.093 \\
$30^{\circ}$ incidence & $\mathrm{A}$ & 1.9182 & 0.8660 & 0.021 \\
& $\mathrm{C}$ & 0.8677 & 0.8660 & 0.196 \\
& $\mathrm{~B}$ & 0.8671 & 1.6901 & 0.127 \\
\hline
\end{tabular}




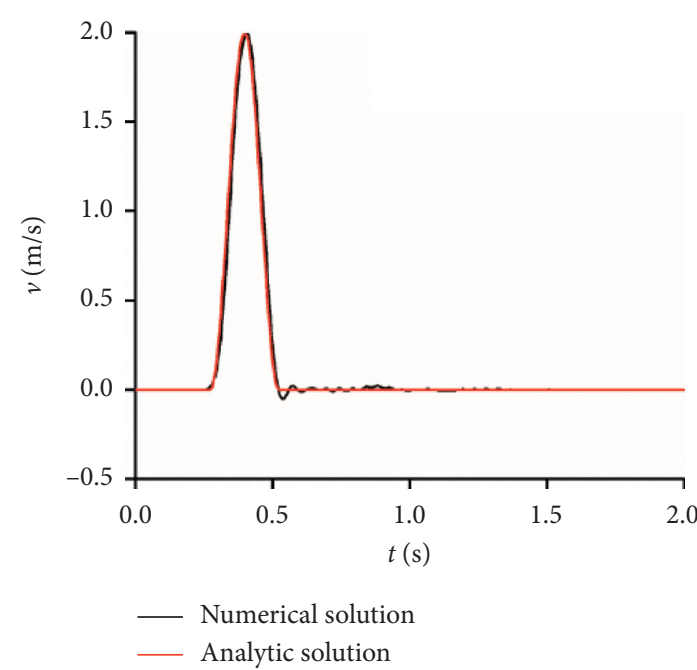

(a)

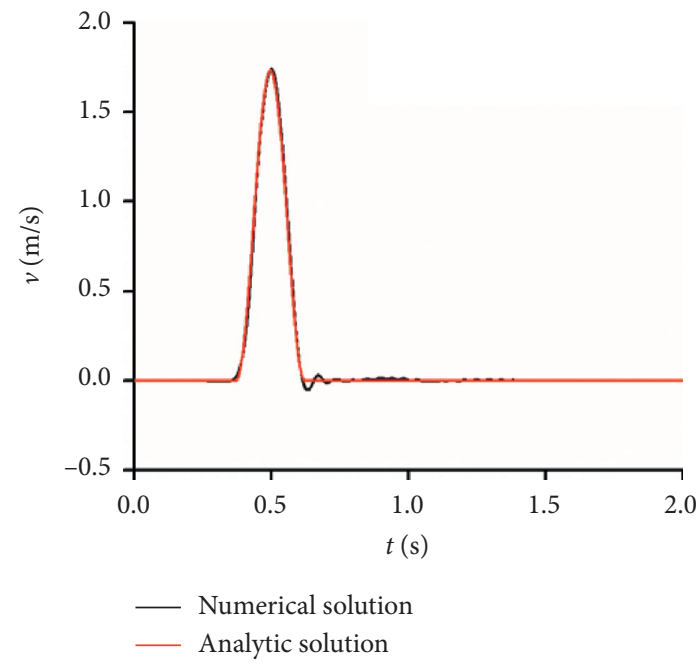

(c)

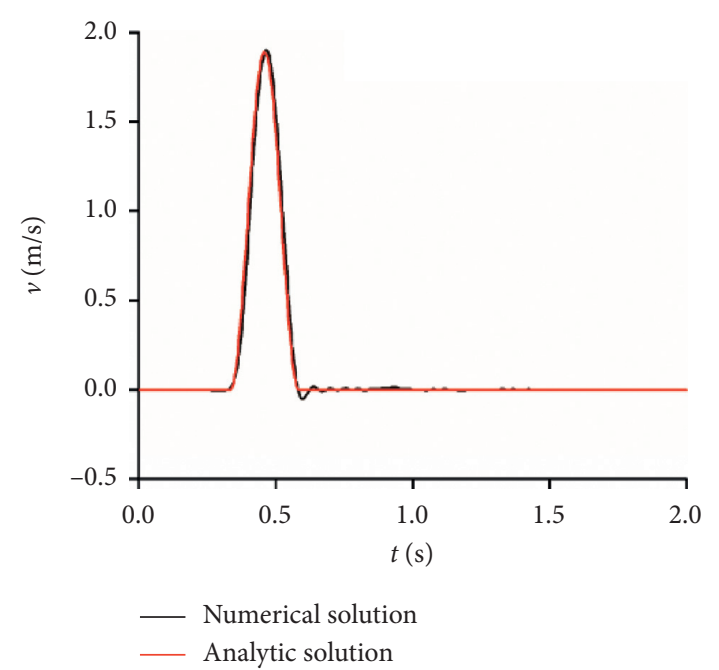

(b)

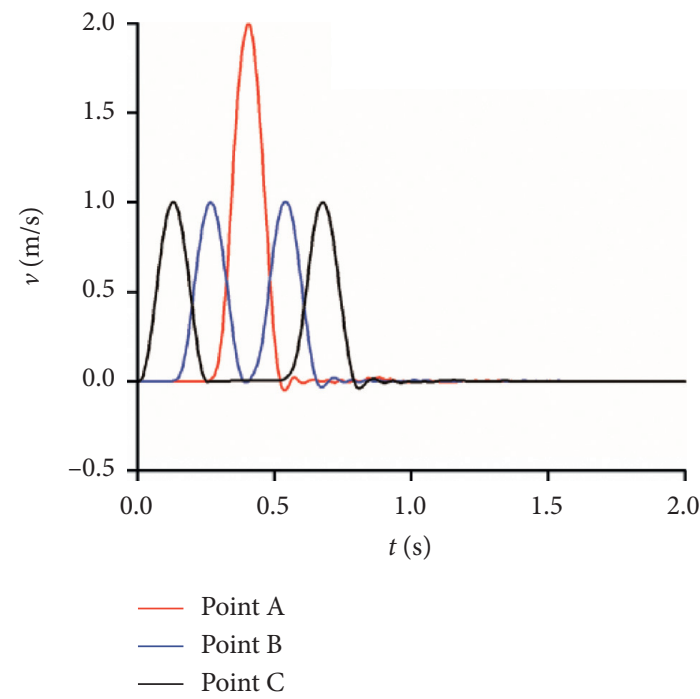

(d)

Figure 7: Time history of X-velocity at observation points under different incident angles. (a) Point A under vertical incidence; (b) point $\mathrm{A}$ under $15^{\circ}$ oblique incidence; (c) point A under $30^{\circ}$ oblique incidence; and (d) observation points under vertical incidence.

TABle 2: Maximum velocity response and error of monitoring point at different incident angles.

\begin{tabular}{lcccc}
\hline Direction of incidence & Observation point & Numerical solution $(\mathrm{m} / \mathrm{s})$ & Analytic solution $(\mathrm{m} / \mathrm{s})$ & Relative error $(\%)$ \\
\hline \multirow{3}{*}{$0^{\circ}$ incidence } & $\mathrm{C}$ & 1.0031 & 1.0000 & 0.31 \\
& $\mathrm{~B}$ & 1.0040 & 1.0000 & 0.4 \\
& $\mathrm{~A}$ & 1.9991 & 0.9000 & 0.045 \\
$15^{\circ}$ incidence & $\mathrm{C}$ & 0.9681 & 0.9654 & 0.22 \\
& $\mathrm{~B}$ & 0.9682 & 1.8926 & 0.29 \\
$30^{\circ}$ incidence & $\mathrm{A}$ & 1.9040 & 0.8660 & 0.60 \\
& $\mathrm{C}$ & 0.8645 & 0.8659 & 0.17 \\
\end{tabular}




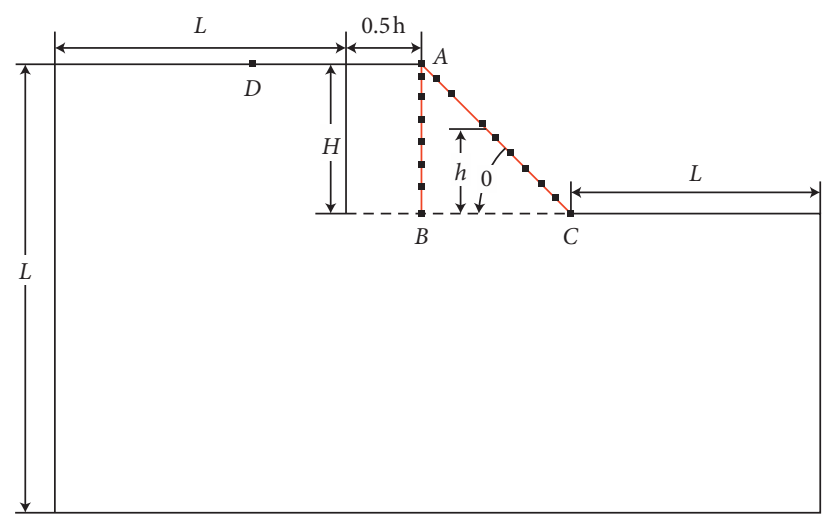

- Monitoring point

Figure 8: Computational model of the slope.

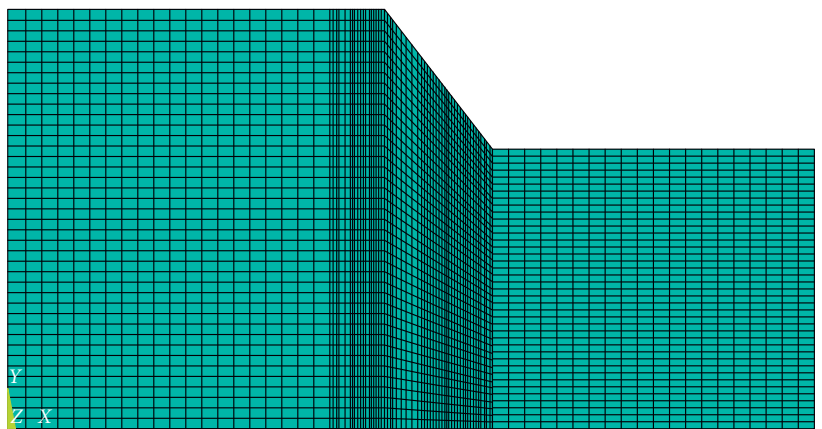

FIgURE 9: FEM mesh of the slope.

TABLE 3: Material parameters.

\begin{tabular}{lccccc}
\hline Parameters & Density $\left(\mathrm{kg} / \mathrm{m}^{3}\right)$ & Elastic module $(\mathrm{GPa})$ & Poisson's ratio & Slope height $(\mathrm{m})$ & $\mathrm{L}(\mathrm{m})$ \\
\hline Value & 2500 & 20 & 0.25 & 100 & 300 \\
\hline
\end{tabular}

\subsection{Dynamic Response of Plane Slope under Obliquely Incident $P$ Waves}

4.1.1. Effect of $P$ Waves on the Seismic Response of the Slope Surface. In the slope calculation model in Figure 8 , the observation points are set along the slope surface. Figures 11(a)-11(c)) show the variation law of PGA amplification coefficient of the slope surface under obliquely incident $\mathrm{P}$ wave in the case of slope angles of $45^{\circ}, 50^{\circ}$, and $60^{\circ}$, respectively, and Figure $11(\mathrm{~d})$ plots the $\mathrm{Y}$-acceleration time history at the observation points $A$ and $D$ under vertical incidence in $\theta=45^{\circ}$. As can be seen from the figure, when the slope angle is constant, the change of incident angle of seismic wave has no obvious effect on PGA amplification coefficient. The PGA amplification coefficient along the slope surface does not increase linearly with the increase of the elevation subjected to obliquely incident $\mathrm{P}$ waves. When $h$ is less than $0.5 \mathrm{H}$, the PGA amplification coefficient fluctuates around 1.0; but as $h$ is larger than $0.5 \mathrm{H}$, the PGA amplification coefficient tends to increase with the increase of the elevation of the slope, especially at the crest of the slope. The PGA amplification coefficient of slope surface is between 0.8 and 1.4, and the PGA amplification coefficient is the largest when vertical incidence occurs.

4.1.2. Effect of $P$ Waves on the Seismic Response of the Slope Vertical Plane $A B$. In the slope calculation model in Figure 8 , the monitoring points are set along the vertical plane $\mathrm{AB}$ at the crest of the slope. The variation of the PGA amplification coefficient in different incident angles $\left(0^{\circ}\right.$ incidence, $15^{\circ}$ incidence, and $30^{\circ}$ incidence) of the vertical plane $\mathrm{AB}$ is depicted in Figure 12 in the case of slope angles of $45^{\circ}, 50^{\circ}$, and $60^{\circ}$, respectively. It can be observed in the figure that the PGA magnification coefficient of vertical plane $\mathrm{AB}$ ranges from 0.9 to 1.4 . When the incident angle is constant, the PGA amplification coefficient generally shows an increasing trend as the elevation increases. The maximum value appears at the crest of the slope. When the slope angle is constant, the PGA amplification factor decreases with the increase of inclination degree of incident $\mathrm{P}$ waves, and the dynamic amplification effect is most significant when vertical incident occurs. 


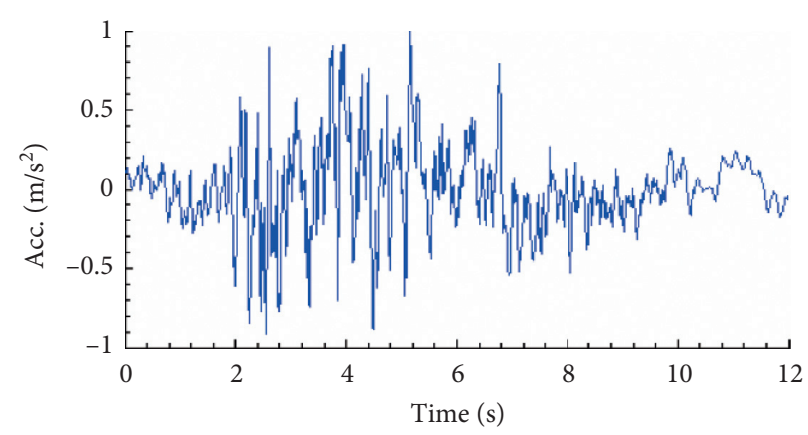

(a)

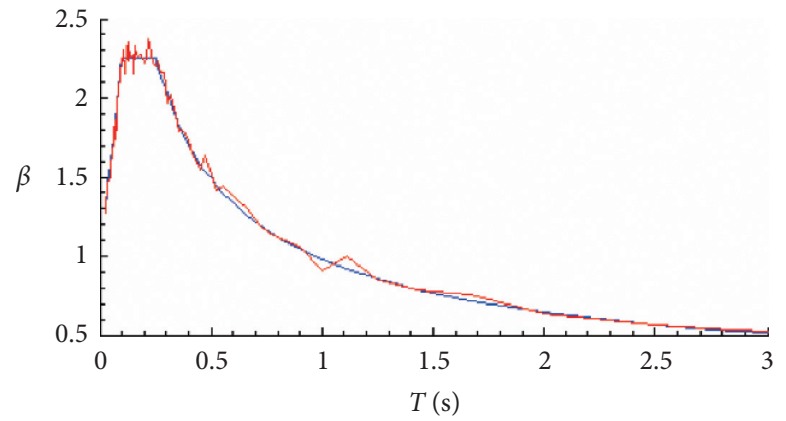

(b)

FIGURE 10: Incident waves and corresponding response spectra.

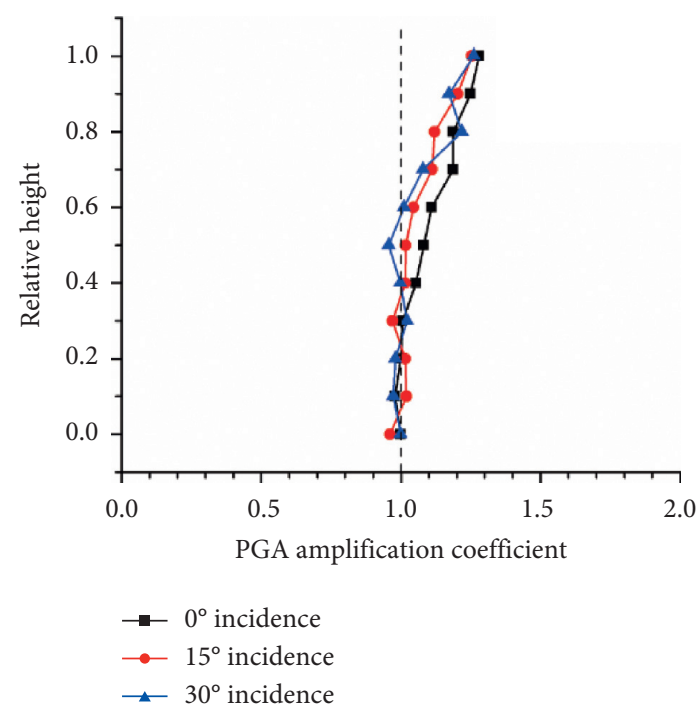

(a)

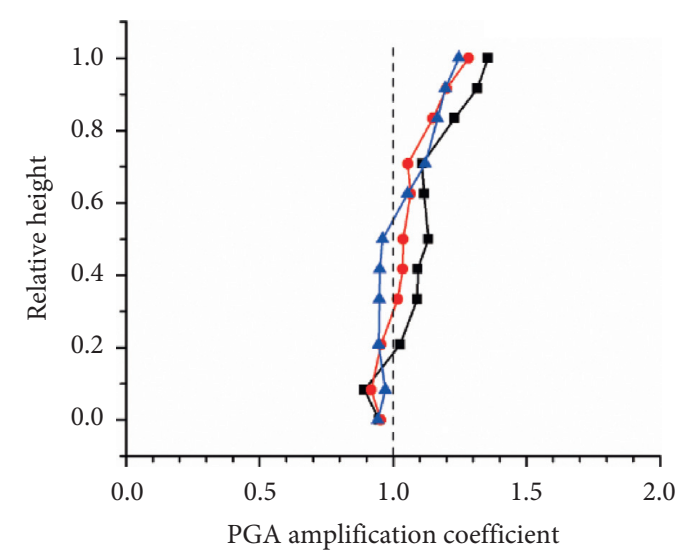

$\rightarrow-0^{\circ}$ incidence
$-\quad 15^{\circ}$ incidence
$\square 30^{\circ}$ incidence

(c)

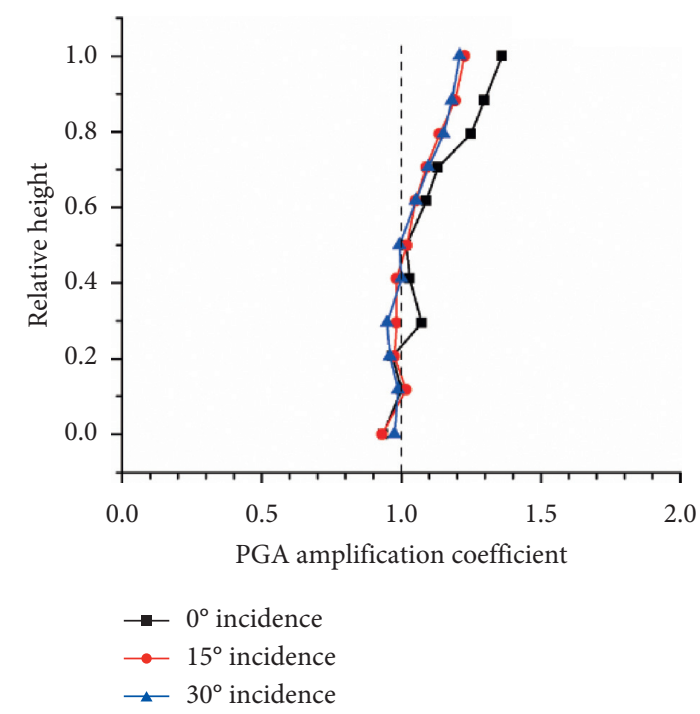

(b)

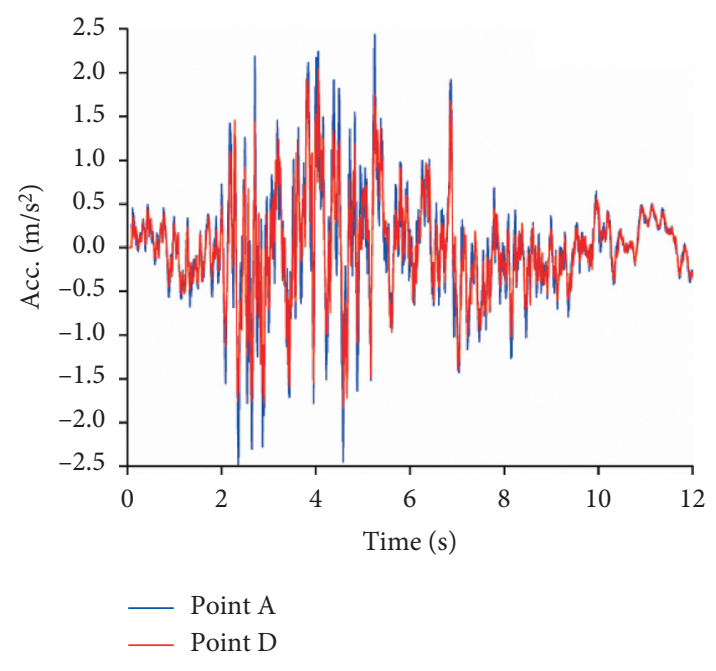

(d)

Figure 11: Distribution law of PGA amplification coefficient along slope surface under P waves. (a) $\theta=45^{\circ}$; (b) $\theta=50^{\circ}$; (c) $\theta=60^{\circ}$; and (d) Y-acceleration time history at the observation points $\mathrm{A}$ and $\mathrm{D}$ under vertical incidence in $\theta=45^{\circ}$. 


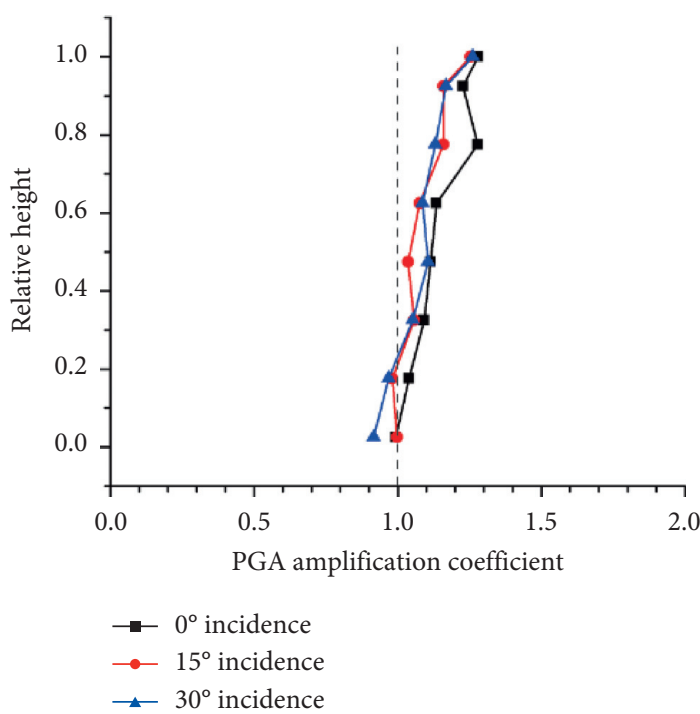

(a)

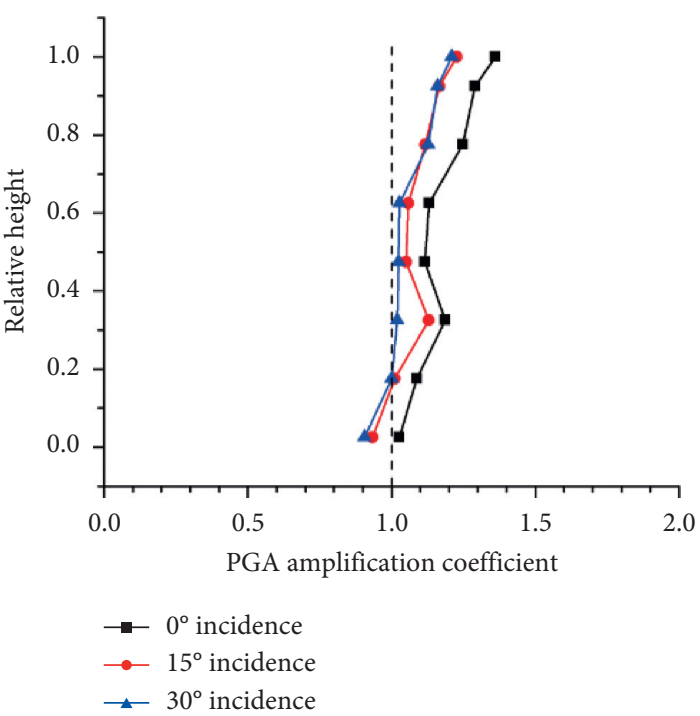

(b)

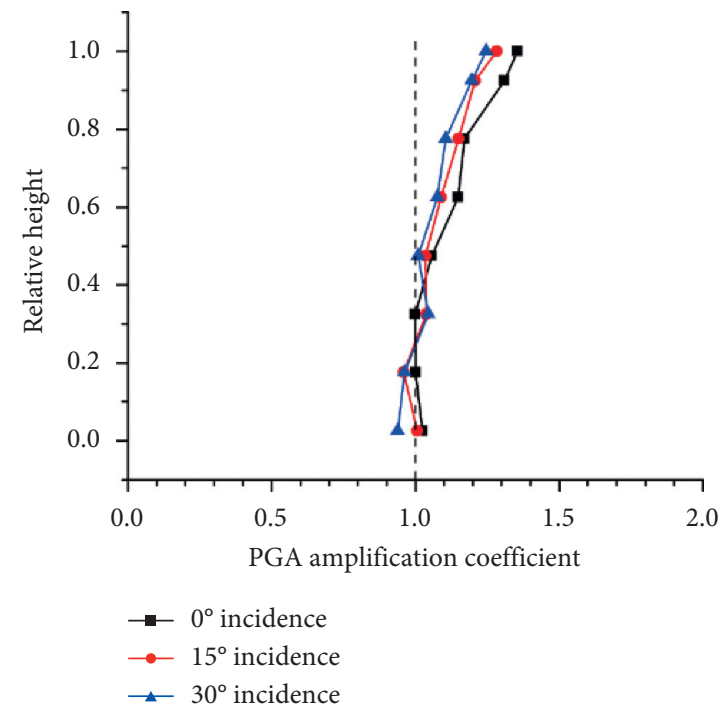

(c)

Figure 12: Distribution law of PGA amplification coefficient of slope vertical plane AB under P waves. (a) $\theta=45^{\circ}$; (b) $\theta=50^{\circ}$; and (c) $\theta=60^{\circ}$.

4.1.3. Effect of Slope Angle on the Seismic Response of Slope Surface. The variations of the seismic response of slope surface have been analyzed under the obliquely incident $\mathrm{P}$ wave in the case of slope angles of $45^{\circ}, 50^{\circ}$, and $60^{\circ}$, respectively. The relationship between PGA amplification coefficient of the slope surface and slope height in different slope angles is illustrated in Figure 13. It is clearly observed that different slope angles have little effect on the seismic response of the slope surface. The PGA amplification coefficient of slope surface is between 0.8 and 1.4.

\subsection{Dynamic Response of Plane Slope under Obliquely Incident SV Waves}

4.2.1. Effect of SV Waves on the Seismic Response of the Slope Surface. According to the theory of wave, it can be seen that when obliquely incident SV waves propagate to the crest of the slope free surface, the wave field will be decomposed into reflected SV waves and reflected $\mathrm{P}$ waves. The complex seismic wave field is formed by the superposition of different wave types, which makes the peak acceleration of each point of the slope increase sharply. The distribution law of PGA amplification coefficient of the slope surface subjected to obliquely incident SV wave is plotted in Figures 14(a)-14(c) in the case of slope angles of $45^{\circ}, 50^{\circ}$, and $60^{\circ}$, respectively. Moreover, Figure 14(d)) plots the X-acceleration time history at the observation points $A$ and $D$ under vertical incidence in $\theta=60^{\circ}$.

It can be seen from the figure that the PGA amplification coefficient of the slope surface increases with the increase of inclination degree of incident SV waves when the slope angle is constant. With the increase of elevation, PGA amplification coefficient of the slope surface increases gradually. The PGA amplification factor is between 0.75 and 1.7. The 


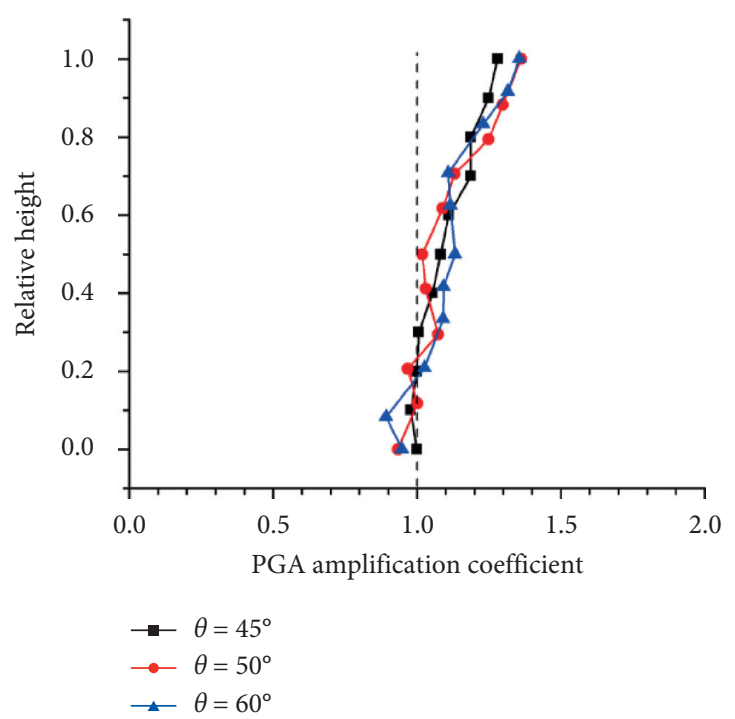

(a)

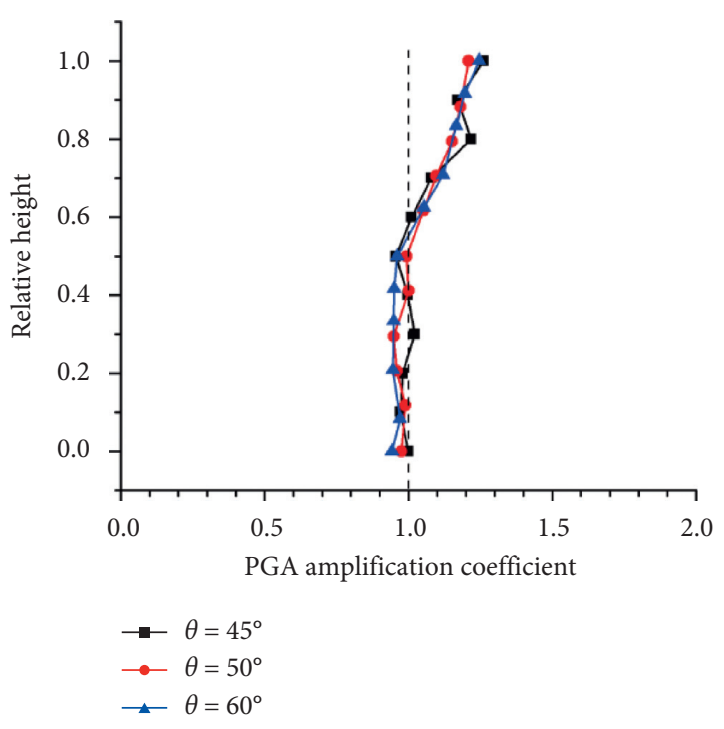

(b)

Figure 13: Distribution law of seismic amplification factor of slope surface in different slope angle. (a) Vertical incidence; (b) $30^{\circ}$ oblique incidence.

maximum PGA amplification factor appears at the crest of the slope. This magnification effect is significant near the crest of the slope, and it increases dramatically. The amplification effect is not obvious near the slope toe with smaller increases.

4.2.2. Effect of $S V$ Waves on the Seismic Response of the Slope Vertical Plane $A B$. Figure 15 shows the variation of the PGA amplification coefficient by obliquely incident SV wave in different incident angles $\left(0^{\circ}\right.$ incidence, $15^{\circ}$ incidence, and $30^{\circ}$ incidence) of the vertical plane $\mathrm{AB}$ at the crest of the slope in the case of slope angles of $45^{\circ}, 50^{\circ}$, and $60^{\circ}$, respectively. It can be seen from the figure that the PGA magnification coefficient of the vertical plane $A B$ ranges from 0.7 to 1.7. In the same vertical plane, the PGA amplification coefficient generally shows an increasing trend with the increase of elevation, and the increasing trend is the most prominent at the crest of the slope. When the slope angle is constant, the PGA amplification factor increases with the increase of the incident angle, and the dynamic amplification effect is minimal when vertical incident occurs.

4.2.3. Effect of Slope Angle on the Seismic Response of Slope Surface. Figure 16 depicts the variation of the seismic response under obliquely incident SV wave in different incident angles $\left(0^{\circ}\right.$ incidence and $30^{\circ}$ incidence) of the vertical plane $A B$ at the crest of the slope in the case of slope angles of $45^{\circ}, 50^{\circ}$, and $60^{\circ}$, respectively. The variation of slope angle has no obvious effect on PGA amplification coefficient near the foot of slope, but as $h$ is larger than $0.5 \mathrm{H}$, the PGA amplification coefficient increases with the increase of the slope angle, showing a linear growth trend along the elevation direction. The amplification degree at the top of slope is the largest, while the amplification effect at the foot of slope is the smallest. In fact, the change of slope angle has little influence on the natural frequency and period of vibration of rock slope, but has great influence on the mode of vibration. Therefore, the change of slope angle has great influence on the seismic dynamic response of rock slope. The overall PGA amplification factor is between 0.75 and 1.7.

\section{Discussion}

A large number of studies on earthquake-induced landslide indicate that the seismic dynamic amplification effect of slope topography is very obvious. Nevertheless, the effect of this factor has not been considered in the current Chinese standard for seismic design of hydraulic structures (GB 51247-2018), and there is no specific provision on the selection of slope seismic action coefficient. In the past few decades, researchers [38] have also verified the existence of seismic amplification effect of slope site through numerical simulation and shaking table test. In most of those works, numerous studies on seismic dynamic response of rock slopes are generally based on the assumption of vertical incidence, and there are scarce studies on dynamic response of rock slope under seismic wave oblique incidence.

On the other hand, the commercially available computer software usually adopts the vertical incident seismic wave method for structural dynamic response analysis, while the seismic input method considering the oblique incidence has not been implemented yet. Some scholars $[15,16]$ have realized the seismic load input method considering oblique incidence through programming and applied the method to computer software to qualitatively study the dynamic response of structures under the action of obliquely incident seismic wave. The innovation of this paper compared with previous studies is that the seismic load input method considering oblique incidence and structural dynamic 


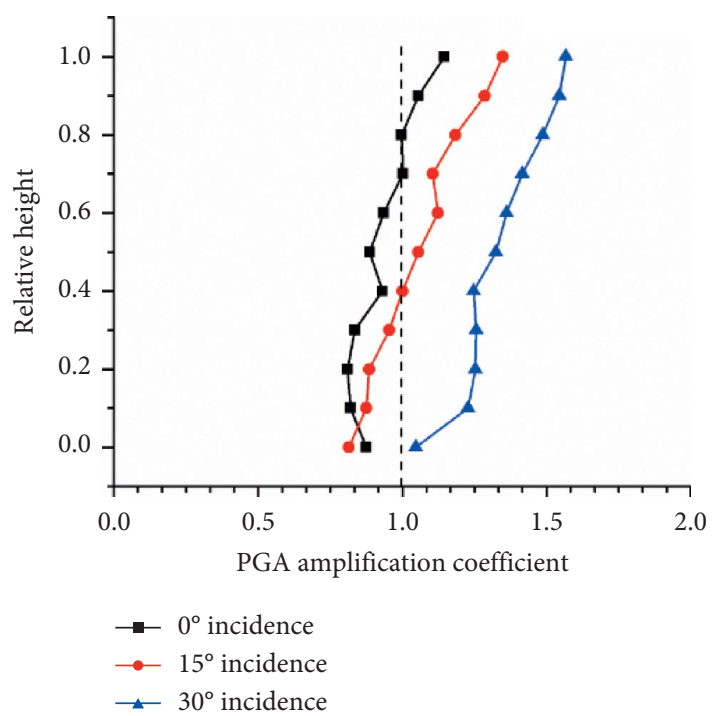

(a)

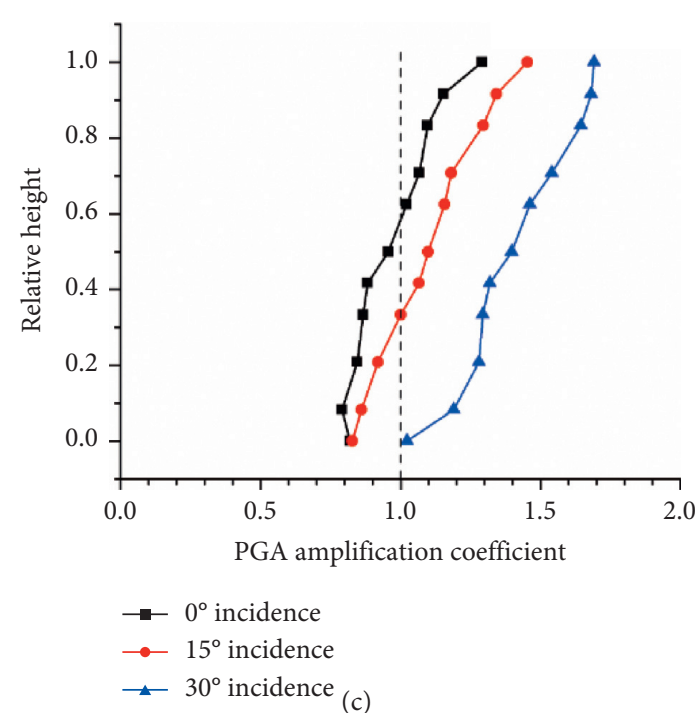

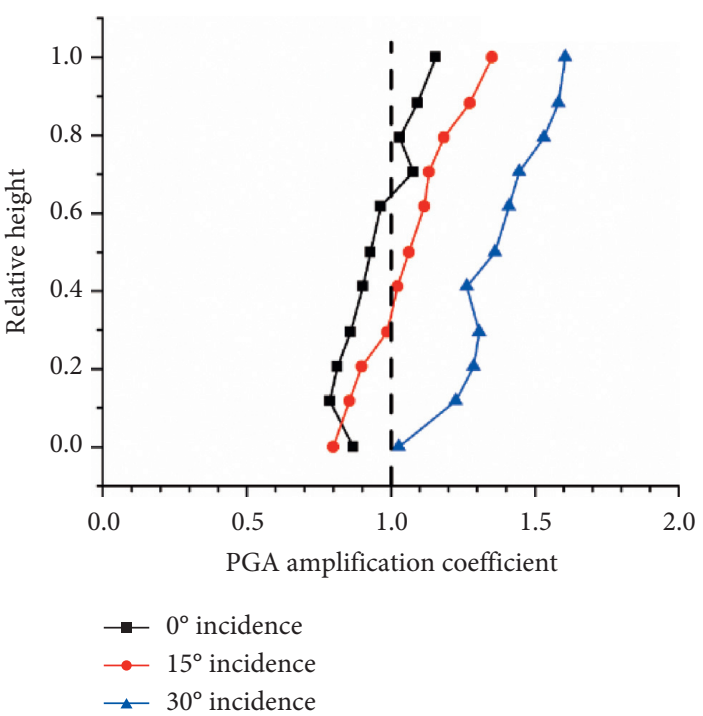

(b)

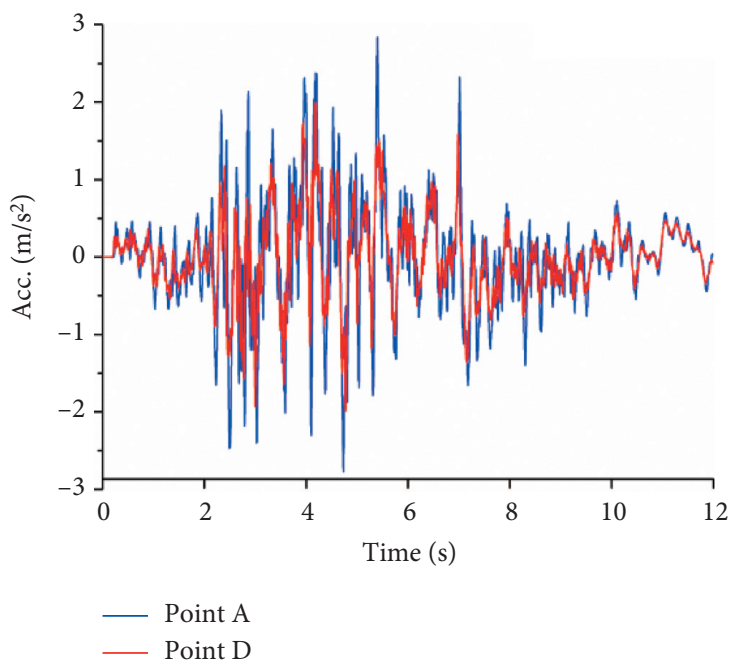

(d)

Figure 14: Distribution law of PGA amplification coefficient of slope surface under the obliquely incident SV wave. (a) $\theta=45^{\circ}$; (b) $\theta=50^{\circ}$; (c) $\theta=60^{\circ}$; and (d) X-acceleration time history at the observation points $A$ and $D$ under vertical incidence in $\theta=60^{\circ}$.

response analysis is realized by using a self-developed program without the use of commercial software.

For the slope seismic input model proposed in this research, we considered the influence of radiation damping on infinite foundations and realized the incidence of seismic waves with arbitrary incident angles by deriving the equivalent nodal load. The above method can also be employed to investigate the seismic response of other structures. The seismic wave parameters and the material parameters of the model can be changed according to the actual situation, so the method proposed in this research is suitable for the finite element dynamic calculation of general plane problems. Through research, the reasonable slope seismic input mechanism and the amplification effect of earthquakes along the slope are determined, which will lay the foundation for the revision of the existing relevant provisions of engineered slopes in water resources and hydropower projects. At the same time, the research results can provide some basis for the pseudostatic method to determine the seismic action coefficient.

The slope is formed by excavation or filling in a semiinfinite rectangular area. Seismic waves passing through mountain topography are subject to localized (de)amplification due to the reflective effect of free surfaces. In order to facilitate the calculation, the simplified slope model is selected for analysis, and this method is also applicable when considering the irregularity of the slope surface.

This paper only studies the homogeneous and continuous elastic rock slope, and further research is required on the seismic response of rock slopes with nonlinear materials. In addition, we have only studied the plane $\mathrm{P}$ wave and SV wave oblique incidence; for different wave type ( $\mathrm{SH}$ wave), different incident seismic waves and the dynamic response rule of threedimensional space structure remain to be further research. 

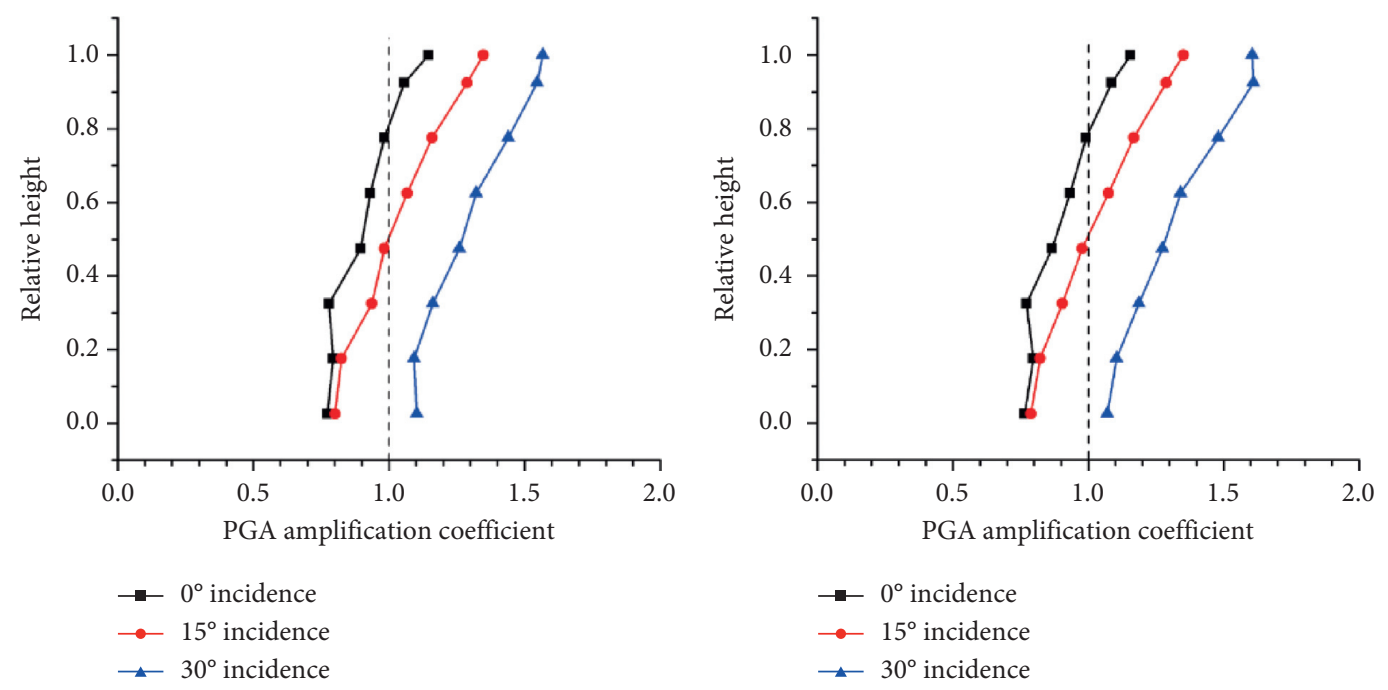

(a)

(b)

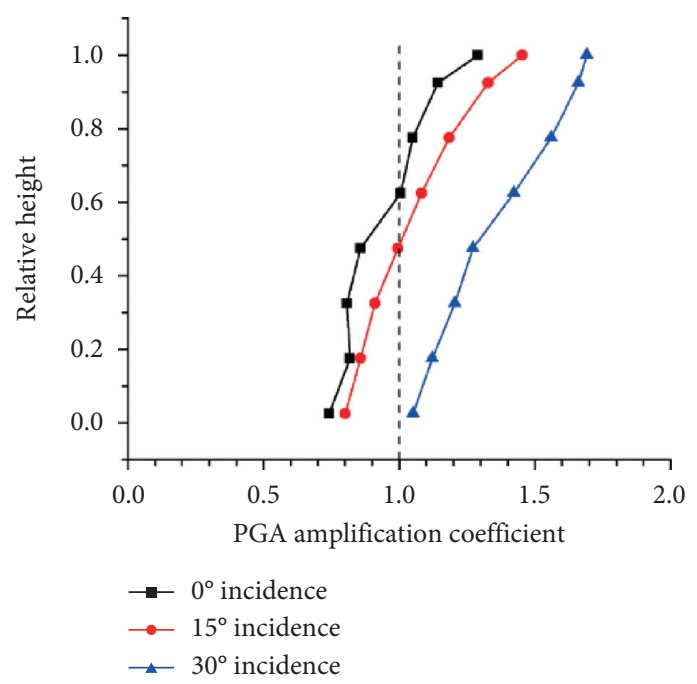

(c)

FIGURE 15: Distribution law of PGA amplification coefficient of slope vertical plane AB under the obliquely incident $\mathrm{SV}$ wave. (a) $\theta=45^{\circ}$; (b) $\theta=50^{\circ}$; and (c) $\theta=60^{\circ}$.

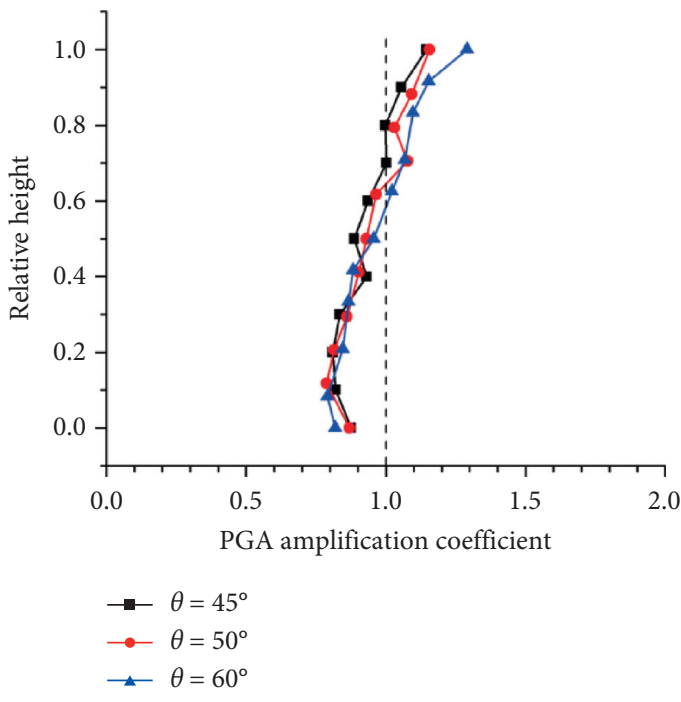

(a)

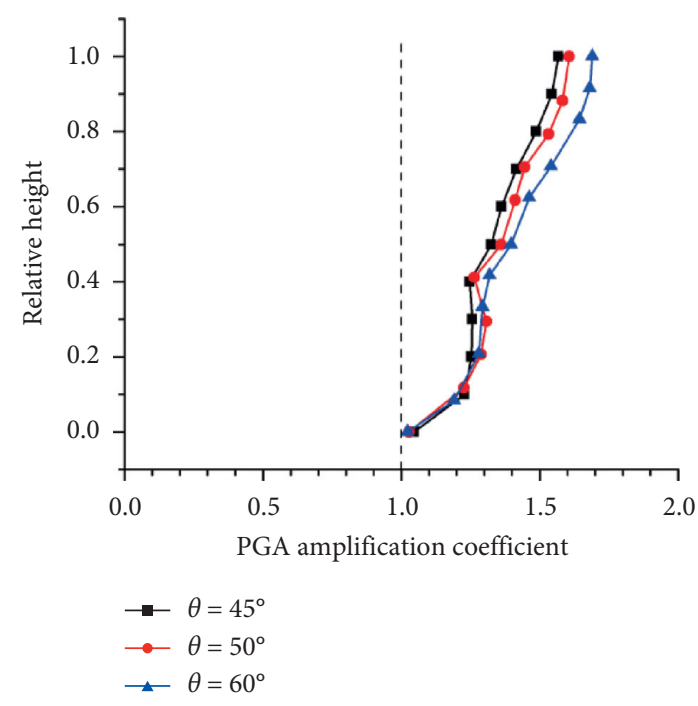

(b)

Figure 16: Distribution law of seismic amplification factor of oblique incidence in different slope angle. (a) Vertical incidence. (b) $30^{\circ}$ oblique incidence. 


\section{Conclusions}

In this paper, the seismic input model of slope is, therefore, proposed to analyze the dynamic response of the rock slope under the obliquely incident seismic wave based on the time-domain wave analysis method. The semi-infinite space numerical example is simulated to verify the validity and accuracy of the model. Based on the established model, the effects of the variation of the seismic wave incident angles and slope angles on the dynamic response of a rock slope are analyzed. Some notable conclusions have been reached:

(1) When P wave is obliquely incident, the change of the incident angle has no obvious influence on the PGA amplification coefficient of slope surface, but the PGA amplification coefficient of vertical plane $A B$ at the crest of the slope decreases with the increase of the incident angle. Overall, PGA amplification coefficient ranges from 0.8 to 1.4.

(2) When the SV wave is obliquely incident, the PGA amplification coefficient of the slope surface and the slope vertical plane $A B$ gradually increase with the increase of the incident angle, and the PGA amplification coefficient is between 0.7 and 1.7.

(3) When the P wave is incident at a certain angle, different slope angles have negligible effect on the seismic response of the slope surface. As the SV wave is incident at a certain angle, the PGA amplification coefficient at the upper part of the slope increases with the increase of the slope angle.

It can be seen that when the SV wave is obliquely incident, the dynamic response of the slope is significantly larger than that of the conventional vertical incidence method; while the $\mathrm{P}$ wave is obliquely incident, the dynamic response of the slope is slightly smaller than that of the vertical incidence. Therefore, it is necessary to consider the influence of obliquely incident seismic waves on the dynamic response of rock slope in the seismic design of major projects in earthquake-prone areas.

\section{Data Availability}

The raw/processed data required to reproduce these findings cannot be shared at this time as the data also form part of an ongoing study.

\section{Conflicts of Interest}

The authors declare that there are no conflicts of interest regarding the publication of this paper.

\section{Acknowledgments}

This research was supported by the specialized scientific research fund project of China Institute of Water Resources and Hydropower Research (EB0145B382016).

\section{References}

[1] Y. B. Tsai, T. M. Yu, H. L. Chao, and C. P. Lee, "Spatial distribution and age dependence of human-fatality rates from the Chi-Chi, Taiwan, earthquake of 21 september 1999," Bulletin of the Seismological Society of America, vol. 91, no. 5, pp. 1298-1309, 2001.

[2] K. J. Shou, L. Y. Fei, J. F. Lee, C.-Y. Wei, S. T. Huang, and Y. C. Lin, "Landslides and catchment sedimentation in the TaChia River influenced by the 1999 Taiwan Chi-Chi earthquake," International Journal of Remote Sensing, vol. 33, no. 15, pp. 4815-4840, 2012.

[3] Y. Yin, F. Wang, and P. Sun, "Landslide hazards triggered by the 2008 Wenchuan earthquake, Sichuan, China," Landslides, vol. 6, no. 2, pp. 139-152, 2009.

[4] L. Dong, J. Wang, X. Li, and K. Peng, "Dynamic stability analysis of rockmass: a review," Advances in Civil Engineering, vol. 2018, Article ID 4270187, 22 pages, 2018.

[5] J. Montgomery, G. Candia, A. Lemnitzer, and A. Martinez, "The September 19, 2017 Mw 7.1 Puebla-Mexico city earthquake: observed rockfall and landslide activity," Soil Dynamics and Earthquake Engineering, vol. 130, Article ID 105972, 2020.

[6] K. W. Franke, G. Candia, J. M. Mayoral et al., "Observed building damage patterns and foundation performance in Mexico city following the 2017 M7.1 Puebla-Mexico City earthquake," Soil Dynamics and Earthquake Engineering, vol. 125, Article ID 105708, 2019.

[7] R. Huang and W. Li, "Development and distribution of geohazards triggered by the 5.12 Wenchuan Earthquake in China," Science in China Series E: Technological Sciences, vol. 52, no. 4, pp. 810-819, 2009.

[8] M. Basharat, J. Rohn, M. S. Baig, and M. R. Khan, "Spatial distribution analysis of mass movements triggered by the 2005 Kashmir earthquake in the northeast hhimalayas of Pakistan," Geomorphology, vol. 206, pp. 203-214, 2014.

[9] B. Liu and B. Zhang, "Study on dynamic response of slope under obliquely incident SV-wave," Materials Science and Engineering, vol. 452, no. 3, Article ID 032090, 2018.

[10] G. D. Bouckovalas and A. G. Papadimitriou, "Numerical evaluation of slope topography effects on seismic ground motion," Soil Dynamics and Earthquake Engineering, vol. 25, no. 7-10, pp. 547-558, 2005.

[11] C. Bourdeau and H.-B. Havenith, "Site effects modelling applied to the slope affected by the suusamyr earthquake (Kyrgyzstan, 1992)," Engineering Geology, vol. 97, no. 3-4, pp. 126-145, 2008.

[12] G. Yang, S. Qi, F. Wu, and Z. Zhan, "Seismic amplification of the anti-dip rock slope and deformation characteristics: a large-scale shaking table test," Soil Dynamics and Earthquake Engineering, vol. 115, pp. 907-916, 2018.

[13] A. Che, H. Yang, B. Wang, and X. Ge, "Wave propagations through jointed rock masses and their effects on the stability of slopes," Engineering Geology, vol. 201, pp. 45-56, 2016.

[14] X. Feng, Q. Jiang, X. Zhang, and H. Zhang, "Shaking table model test on the dynamic response of anti-dip rock slope," Geotechnical and Geological Engineering, vol. 37, no. 3, pp. 1211-1221, 2019.

[15] G. Fan, L. M. Zhang, X. Y. Li, R. L. Fan, and J. J. Zhang, "Dynamic response of rock slopes to oblique incident SV waves," Engineering Geology, vol. 247, pp. 94-103, 2018.

[16] J. Q. Huang, X. L. Du, M. Zhao, and X. Zhao, "Impact of incident angles of earthquake shear (S) waves on 3-D non- 
linear seismic responses of long lined tunnels," Engineering Geology, vol. 222, pp. 168-185, 2017.

[17] P. Alfaro, J. Delgado, F. J. García-Tortosa et al., "The role of near-field interaction between seismic waves and slope on the triggering of a rockslide at Lorca (SE Spain)," Natural Hazards and Earth System Sciences, vol. 12, no. 12, pp. 3631-3643, 2012.

[18] J. Huang, M. Zhao, and X. Du, "Non-linear seismic responses of tunnels within normal fault ground under obliquely incident P waves," Tunnelling and Underground Space Technology, vol. 61, pp. 26-39, 2017.

[19] F. García, J. J. Aznárez, L. A. Padrón, and O. Maeso, "Relevance of the incidence angle of the seismic waves on the dynamic response of arch dams," Soil Dynamics and Earthquake Engineering, vol. 90, pp. 442-453, 2016.

[20] L. Yan, A. Haider, P. Li, and E. Song, "A numerical study on the transverse seismic response of lined circular tunnels under obliquely incident asynchronous $\mathrm{P}$ and SV waves," Tunnelling and Underground Space Technology, vol. 97, Article ID $103235,2020$.

[21] M. Á. Guillermo, A. P. Luis, J. J. Aznáez, and O. Maeso, "Structure-soil-structure interaction effects on the dynamic response of piled structures under obliquely incident seismic shear waves," Soil Dynamics and Earthquake Engineering, vol. 78, pp. 142-153, 2015.

[22] C. Zhu, D. P. Thambiratnam, and J. Zhang, "Response of sedimentary basin to obliquely incident $\mathrm{SH}$ waves," Bulletin of Earthquake Engineering, vol. 14, no. 3, pp. 647-671, 2015.

[23] L. Lenti and S. Martino, "The interaction of seismic waves with step-like slopes and its influence on landslide movements," Engineering Geology, vol. 126, pp. 19-36, 2012.

[24] D. Song, A. Che, R. Zhu, and X. Ge, "Dynamic response characteristics of a rock slope with discontinuous joints under the combined action of earthquakes and rapid water drawdown," Landslides, vol. 15, no. 6, pp. 1109-1125, 2017.

[25] E. Kausel and J. L. Tassoulas, "Transmitting boundaries: a closed-form comparison," Bulletin of the Seismological Society of America, vol. 71, no. 1, pp. 143-159, 1981.

[26] Z. Zhang, J. A. Fleurisson, and F. Pellet, "The effects of slope topography on acceleration amplification and interaction between slope topography and seismic input motion," Soil Dynamics and Earthquake Engineering, vol. 113, pp. 420-431, 2018.

[27] J. Pan, C. Zhang, J. Wang, and Y. Xu, "Seismic damagecracking analysis of arch dams using different earthquake input mechanisms," Science in China Series E: Technological Sciences, vol. 52, no. 2, pp. 518-529, 2009.

[28] J. Liu, Y. Du, X. Du, Z. Wang, and J. Wu, “3D viscous-spring artificial boundary in time domain," Earthquake Engineering and Engineering Vibration, vol. 5, no. 1, pp. 93-102, 2006.

[29] A. J. Deeks and M. F. Randolph, "Axisymmetric time-domain transmitting boundaries," Journal of Engineering Mechanics, vol. 120, no. 1, pp. 25-42, 1994.

[30] X. Du and M. Zhao, "A local time-domain transmitting boundary for simulating cylindrical elastic wave propagation in infinite media," Soil Dynamics and Earthquake Engineering, vol. 30, no. 10, pp. 937-946, 2010.

[31] W. Qiao and G. M. Liu, "Dynamic analysis of artificial boundaries in gravity dam-foundation rock interaction system," Applied Mechanics and Materials, vol. 580-583, pp. 1680-1686, 2014.

[32] J. Q. Huang, X. L. Du, L. Jin, and M. Zhao, "Impact of incident angles of $\mathrm{P}$ waves on the dynamic responses of long lined tunnels," Earthquake Engineering \& Structural Dynamics, vol. 45, no. 15, pp. 2435-2454, 2016.
[33] J. B. Liu and Y. D. Lu, "A direct method for analysis of dynamic soil-structure interaction based on interface idea," Developments in Geotechnical Engineering, vol. 83, pp. 261276, 1998.

[34] K. Haciefendioğlu, "Influence of soil conditions on the stochastic response of asphaltic lining dams to spatially varying ground motions," Journal of Structural Engineering \& Applied Mechanics, vol. 1, no. 4, pp. 155-163, 2019.

[35] V. Saouma, F. Miura, G. Lebon, and Y. Yagome, "A simplified 3D model for soil-structure interaction with radiation damping and free field input," Bulletin of Earthquake Engineering, vol. 9, no. 5, pp. 1387-1402, 2011.

[36] R. Lerch, "Simulation of piezoelectric devices by two- and three-dimensional finite elements," IEEE Transactions on Ultrasonics, Ferroelectrics and Frequency Control, vol. 37, no. 3, pp. 233-247, 1990.

[37] Y. Li, T. Li, and L. Zhao, "Study on distribution of seismic coefficient for rock slopes," in Earth and Space 2012: Engineering, Science, Construction, and Operations in Challenging Environments, pp. 1003-1014, American Society of Civil Engineers, Reston, VA, USA, 2012.

[38] H. X. Liu, Q. Xu, and Y. R. Li, "Effect of lithology and structure on seismic response of steep slope in a shaking table test," Journal of Mountain Science, vol. 11, no. 2, pp. 371-383, 2014. 